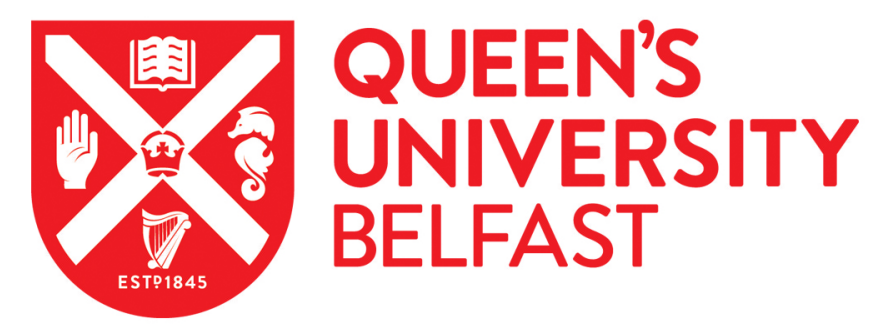

\title{
Semi-empirical wake structure model of tidal turbine using joint axial momentum theory and DES-SA method
}

Wang, S., Lam, W-H., Cui, Y., Zhang, T., Jang, J., Sun, C., Guo, J., Ma, Y., \& Hamill, G. (2019). Semi-empirical wake structure model of tidal turbine using joint axial momentum theory and DES-SA method. Ocean Engineering, 191. https://doi.org/10.1016/j.oceaneng.2019.106525

\section{Published in: \\ Ocean Engineering}

\section{Document Version:}

Peer reviewed version

Queen's University Belfast - Research Portal:

Link to publication record in Queen's University Belfast Research Portal

\section{Publisher rights}

(c) 2019 Elsevier Ltd.

This manuscript version is made available under the CC-BY-NC-ND 4.0 license http://creativecommons.org/licenses/by-nc-nd/4.0/,which permits distribution and reproduction for non-commercial purposes, provided the author and source are cited.

\section{General rights}

Copyright for the publications made accessible via the Queen's University Belfast Research Portal is retained by the author(s) and / or other copyright owners and it is a condition of accessing these publications that users recognise and abide by the legal requirements associated with these rights.

Take down policy

The Research Portal is Queen's institutional repository that provides access to Queen's research output. Every effort has been made to ensure that content in the Research Portal does not infringe any person's rights, or applicable UK laws. If you discover content in the Research Portal that you believe breaches copyright or violates any law, please contact openaccess@qub.ac.uk. 


\title{
Semi-empirical wake structure model of rotors using joint axial momentum theory and DES-SA method
}

\author{
Shuguang Wang ${ }^{12}$, Wei-Haur Lam ${ }^{12 *}$, Yonggang Cui ${ }^{12}$, Tianming Zhang ${ }^{12}$, Jinxin \\ Jiang $^{12}$, Chong Sun ${ }^{12}$, Jianhua Guo ${ }^{12}$, Yanbo $\mathrm{Ma}^{12}$, Gerard Hamill ${ }^{3}$ \\ ${ }^{\mathbf{1}}$ State Key Laboratory of Hydraulic Engineering Simulation and Safety, Tianjin \\ University, People's Republic of China \\ ${ }^{2}$ First R\&D Services, A-08-16 M Suites, 283 Jalan Ampang, 50450 Kuala Lumpur, \\ Malaysia. \\ ${ }^{3}$ School of Natural and Built Environment, Architecture, Civil \& Structural \\ Engineering and Planning, David Keir Building, Stranmillis Road, Belfast, BT9 5AG, \\ United Kingdom. \\ Corresponding email: wlam@tju.edu.cn; joshuawhlam@hotmail.com
}

\begin{abstract}
CFD simulation with DES-SA turbulence model are conducted to investigate the wake velocity characteristics. The turbine wake velocity distribution of axial, tangential and radial component is analysed by comparing numerical results with previous the experimental and theoretical results. The axial velocity component is continuously recovered along the axial direction. Based on the position of minimum axial velocity, turbine wake can be divided into two zones: zone of flow establishment and zone of established flow. In the zone of flow establishment, two-dipped velocity valleys of the axial velocity distribution appear along the radial direction. These two valleys are combined to one valley at the rotation axis in the zone of established flow. The tangential velocity component is the second largest and the radial velocity component accounts for only a small proportion. Both of tangential and radial velocity decreases along the axial direction. Two velocity peaks of both tangential and radial velocity appear along the radial direction. Several empirical equations of turbine wake are proposed to describe the velocity distribution.
\end{abstract}

Keywords: Tidal-current turbine, Wake model, Velocity distribution, Empirical equation 


\section{Introduction}

The global pressure on energy exploration and supply is increasing, as the world's population and the economy grow. At present, the global energy consumption is still dominated by fossil fuels, but the massive use of fossil fuels inevitably leads to serious environmental pollution and a great number of growing global security problems [1]. About $71 \%$ of the Earth's surface is covered by oceans, which enjoys abundant marine renewable energy sources such as marine wind, tidal energy, wave energy, tidal current energy, temperature differential energy and salt differential energy. The world's ocean energy can be converted into electricity up to 20000 , even 92000 TWh in theory [2]. Tidal current energy is a better renewable energy source, compared with several other forms of renewable energy, for the tidal current energy is highly predictable and with a strong regularity. Still, its energy flux density, high stability and wide distribution are suitable for large-scale development. As an environmental and clean energy source, the development and utilization of tidal current energy do not pollute the marine environment.

Renewable development and utilization of the ocean depend on the continuous progress of its power generation devices [3], Horizontal-axis tidal current turbine is of great efficiency and most widely used, compared to several other forms of power generation device. When the water flows through the turbine, a boundary layer is formed on the boundary of the turbine. The water is separated from the boundary layer and an initial turbine wake is formed. With the wake develops, a swirling zone is generated in downstream of the turbine. Sanderse divided Turbine wake into two areas, near-field wake and far-field wake. Near-field wake is referred to the wake of a rotor diameter region of the turbine, therefore, the wake of the far field is the downstream of flow area [4]. When fluid flows through the rotating turbine, the free stream will be disturbed, moreover, the flow direction and flow rate will have some changes. Those changes in the flow is the effect of turbine wake. Therefore, the turbine wake research is of great significance for the use of tidal current energy, the analysis of surrounding flow field, the calculation of load and fluid properties. Meanwhile, the rational arrangement of turbine arrays in tidal current energy farms is highly improved to reduce the interference of the wake, to improve the efficiency and economics of the overall trend of the power field.

\section{Methodology}

In this paper, the CFD simulations of horizontal-axis tidal-current turbine wake are conducted and semi-empirical wake structure model of tidal turbine will be analysed by comparing CFD results with theoretical results and previous experimental results.

\subsection{Wake structure model of horizontal-axis tidal turbine}

Blades are the most important part and determine the performance and wake distribution of turbine. Many researchers focus on loads acting on blades and the energy extraction efficiency of tidal turbine. They have developed several theories and methods to evaluate the performance of blade including the momentum theory [5], the blade element theory [6], the blade element momentum theory [7], lifting line method 
[8], the lifting surface method [9] and the panel method [10].

However, the theoretical study about wake distribution of tidal turbine is stilling lacking. Due to the similarity between the propeller jet and turbine wake, the theoretical research of tidal turbine can draw lessons from propeller. The axial momentum theory is widely used to predict the efflux velocity within a ship's propeller. The plain water jet investigation of Albertson et al was based on the axial momentum theory [11] and being the basis for all propeller jet researches. Blaauw, Berger, Verhey and Hamill et al all used the axial momentum theory to describe the wake characteristics of a ship's propeller [12-15]. Based on the fundamental works of ship propeller jet in Hamill et al. and Lam et al. Lam \& Chen proposed two equations to predict the efflux velocity and its lateral velocity distribution at various cross sections along the rotation axis [16] and established the prediction model for horizontal-axis turbine wake [17]. Jiang et al. established a ship twin-propeller jet model for predicting velocity distribution within the diffusing jet [18]. Ma et al. proposed two equations to predict the mean velocity within the wake of a vertical-axis turbine [19]. Some researches including the scour induced by turbine wake was also studied by Zhang et al. [20] and Sun et al. [21].

Experiment and numerical methods are two available methods used to study turbine wake. The experimental method can obtain the actual flow field, but it is usually costly. Scale effect between prototype and numerical model cannot be ignored even under the same conditions by using the small-scale flow similarity model. The numerical simulation can obtain the detail information of entire flow field by solving the equations of fluid motion, but some variation occurs in the calculation results. In this paper, the numerical simulation is developed to obtain the wake field at different conditions. The semi-empirical wake structure model is proposed by comparing the numerical results with the previous theoretical and experimental results.

\subsubsection{Axial velocity}

The successful application of axial momentum theory in propeller jet prediction provides a reference method for the study of axial velocity distribution of a horizontal-axis tidal-current turbine. Based on the tidal turbine actuator disc model (Fig. 1), Lam used the axial momentum theory and Gaussian probability distribution to propose the efflux velocity (Eq. 1) and the lateral velocity distribution equation (Eq. 2) of a turbine wake [16]. 


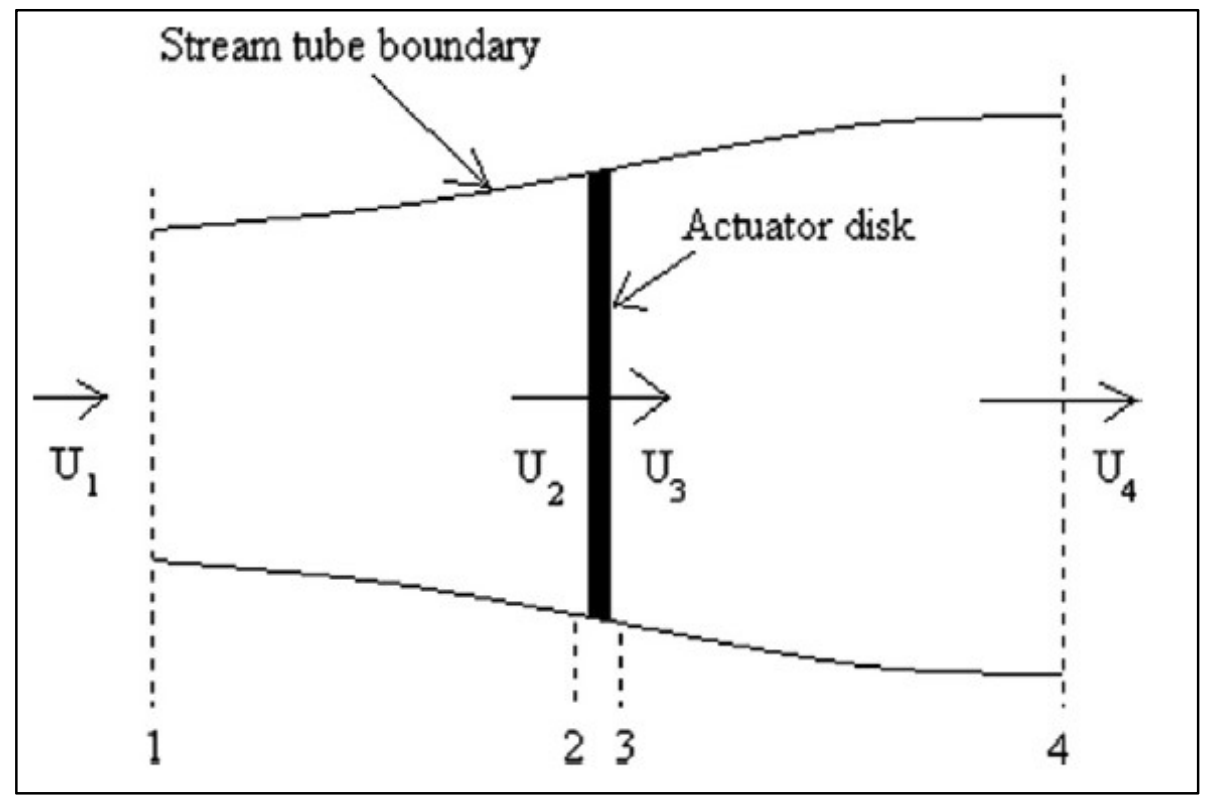

Fig. 1 The tidal turbine actuator disc model [16]

$$
\begin{gathered}
V_{0}=\sqrt{V_{\infty}^{2}-\left(1.59 n D \sqrt{C_{T}}\right)^{2}} \\
V_{x, r}=V_{\infty}-\left(V_{\infty}-V_{\min }\right) e^{\left[-\left((r+0.081 x-(D / 2))^{2} /\left(2(0.081 x)^{2}\right)\right)\right]}
\end{gathered}
$$

By using these two equations, the predicted turbine wake profile along the downstream direction could be finally illustrated in Fig. 2.

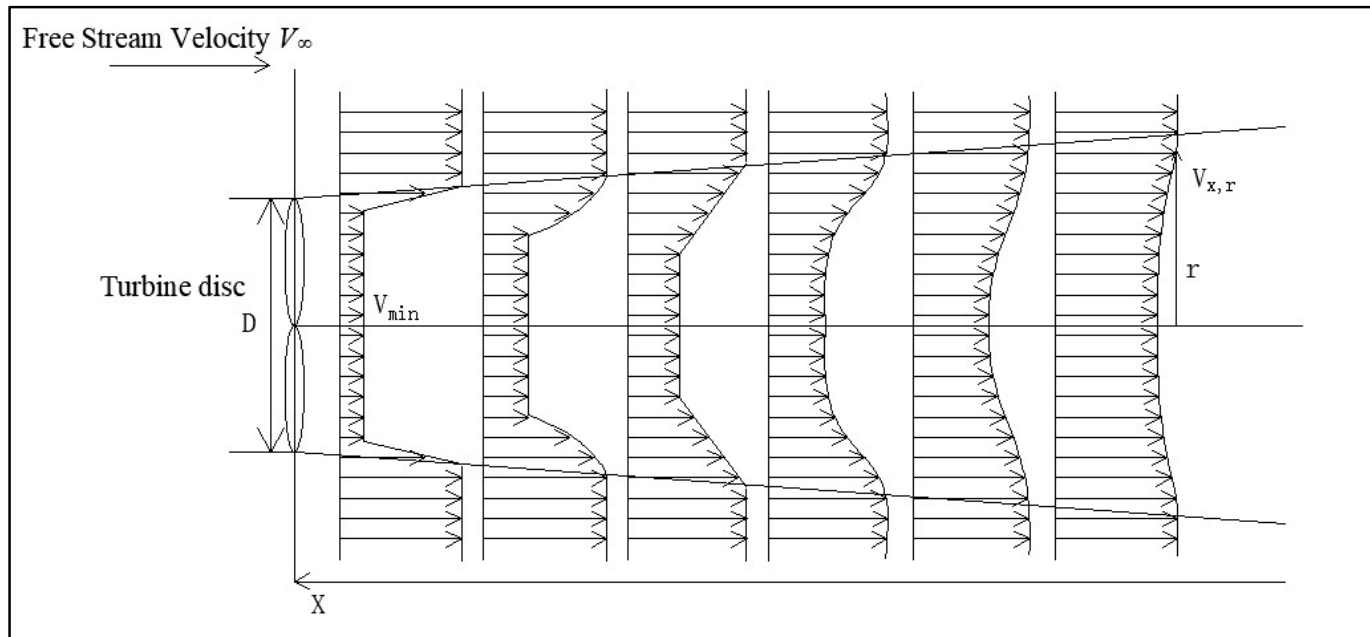

Fig. 2 The predicted turbine wake profile along the downstream direction [16]

Lam et al. proposed an effective method to predict the axial velocity distribution along the downstream: firstly, take the minimum velocity at the turbine disc as the efflux velocity of turbine wake which can be calculated based on the axial momentum theory. Then take the efflux velocity as an input to calculate the velocity deficit and get the lateral velocity distribution along the downstream direction. But this method 
still has several aspects could be improved to get a more realistic turbine wake profile. It does not show the change of efflux velocity in the turbine disc. In fact, the efflux velocity at different radius is not the same and only the blades effects on turbine wake are taken into consideration in this method, while the real turbine wake would be the combination of the wake produced by blades, junctions, hub and the support.

The improvement work on the prediction of efflux velocity of turbine wake is carried out by using CFD analysis in this paper. Based on Lam's work, three-dimensional CFD numerical simulation of turbine wake are conducted and the flow field of tidal turbine is further analysed by comparing numerical results with previous experimental results. An improved efflux velocity equation is suggested and a semi-empirical wake structure is proposed by considering the different efflux velocity along the radial direction of turbine disc and the effects of hub and junctions.

\subsubsection{Tangential and radial velocities}

In contrast to the plain jet research, the rotation of ship's propeller and tidal current turbine causes the surrounding fluid to make a rotational movement around the axis of rotation. Li \& Calisal proposed a cost-effective vortex method which could calculated the induced tangential velocity and tangential force coefficient with lift and drag coefficient [22]. Churchfield et al highlighted the importance of the application of tangential forces by the turbine model in recreating the wake asymmetry that exists behind actual turbines and indicated a lack of comparison to experimental wake data behind turbines [23]. Kang et al carried out a large-eddy simulation (LES) and showed that the interaction of the outer region of the flow with the processing hub vortex would also cause the rotational component of the wake to decay which indicated the effects of hub on the tangential velocity of turbine wake [24]. Actually, most research are still focused on the performance of tidal turbine and there is not enough research on the tangential and radial velocity distribution. The tangential velocity and radial velocity distribution of tidal current turbine wake will be analysed by comparing the CFD simulation results and Lam's experimental results of propeller jet. The study of tangential / radial velocity distribution will be introduced in position of the maximum tangential / radial velocity, decay of the maximum tangential / radial velocity and lateral velocity distribution of tangential / radial velocity.

\subsection{Numerical simulations}

The RANS model is widely used for most problems in engineering with simplicity, high efficiency and low requirement on grid. However, the main drawback is that there is no universal RANS model and it cannot obtain the ripple value at different times. The LES model is more general, versatile and suitable for many complex flows, but it has strict requirements on grid, especially the grid in the boundary layer. Too much grid leads to huge time consuming. Considering the pros and cons of RANS and LES methods, a joint RANS/LES method was proposed to balance the computational cost and accuracy of numerical simulation. Spalart first proposed the DES97 model in 1997 [25]. And then many researchers suggested using DES method to simulate high Reynolds number and large separation flow. Ferreira et al. compared the flow field data obtained from PIV experiments with the results of various turbulence model 
simulations and found that the numerical simulation results of the DES model are superior to the RANS model and LES model [26]. Travin et al. used DES model to simulate the flow around a cylinder. The results predicted the separation and turbulent separation of laminar flow more accurately than the RANS model [27]. The research of turbine conducted by Lee et al, Xiao et al, Zhan et al and Huang et al all showed the superiority of DES simulation [28-31]. However, the DES model has some shortcomings in capturing RANS / LES boundary turbulence information. The LES model may take effect earlier in the boundary layer where the grid resolution does not meet the requirements of LES model. Therefore, Spalart et al proposed DDES, ZDES and IDDES models successively and revised the DES model $[32,33]$.

\subsubsection{CFD simulation settings}

The fluent software is used to do the 3D numerical simulation for predicting the wake distribution of a horizontal-axis tidal turbine. The 3-blade turbine model and boundary conditions are set totally based on Whale's experiment model [34] so that part experimental results can be used to validate CFD results of turbine wake. Further simulation is also conducted by changing the number of blade and rotating speed of turbine to study the influence of solidity and tip speed ratio (TSR). A cylindrical domain was used with a larger size than the experiment tunnel to reduce the interference of boundary with CFD results. the settings of Whale's experiment and CFD simulation are shown in Table 1.

Table 1 The settings of Whale's experiment and CFD simulation

\begin{tabular}{ccc}
\hline Items & Whale's experiment & CFD simulation \\
\hline Domain size (m) & $\begin{array}{c}\text { Cuboid with 10x0.4x0.75 } \\
\text { (water depth) }\end{array}$ & Cylinder with 1.4x 1.0 \\
Rotor diameter (m) & 0.2 & 0.2 \\
Number of blades & 3 & $2,3,4,5,6$ \\
Rotation speed & Variable with TSR (7.4, \\
$(\mathrm{rad} / \mathrm{s})$ & $12.486,14.798)$ & Variable with TSR $(7.4,12.486$, \\
& 0.4 & 0.4 \\
\hline
\end{tabular}

The sliding mesh model is chosen to simulate the turbine rotation, as it is the most accurate for solving multi-motion reference system. The other numerical settings of the simulation in Fluent are shown in Table 2. The choice of turbulence model and grids will discuss in next section. 


\begin{tabular}{cc}
\hline Differential items & Numerical algorithm \\
\hline Scheme & SIMPLE \\
Gradient & Least Squares Cell Based \\
Pressure & Second Order \\
Momentum & Second Order Upwind \\
Turbulent Kinetic Energy & Second Order Upwind \\
Turbulent Dissipation Rate & Second Order Upwind
\end{tabular}

\subsubsection{DES turbulence model}

The basic idea of the DES method used in this paper is that the RANS model is used inside the boundary layer and the LES model is used outside the boundary layer. As all the DES turbulence models are modified by the corresponding RANS models, the basic principles of DES-SA model are introduced as an example in this paper.

Modelling equations of the Spalart-Allmaras model are introduced in Ref. [35]. The main difference between DES-SA and SA model is the definition of length scale. The standard SA model uses the distance to the closest wall as the definition for the length scale, which plays a major role in determining the level of production and destruction of turbulent viscosity. The DES model replaces $d$ everywhere with a new length scale $\tilde{d}$, defined as

$$
\tilde{d}=\min \left(d, C_{d e s} \Delta_{\max }\right)
$$

Where the empirical constant $C_{\text {des }}$ has a value of 0.65 . The grid spacing $\Delta_{\max }$ is based on the largest grid space in the $x, y$ or $z$ directions forming the computational cell. It can be given by

$$
\Delta_{\max }=\max (\delta x, \delta y, \delta z)
$$

The effect of this design is that the traditional Spalart-Allmaras model will be active near the wall, usually inside the boundary layer, and the LES model will be active outside the boundary layer. Therefore, an anisotropic grid can be arranged in the boundary layer according to the requirements of RANS model (RANS generally only has high requirements for grids in the direction of the vertical wall), which greatly reduces the number of grids and reduces the calculation cost. 


\subsubsection{Structure grid}

Grid generation is time-consuming as most flows involve complex geometries which are not readily fit with Cartesian grids. And it highly related to the accuracy of CFD results. Different turbulence models have different requirements for gird generation. The method of grid generation based on DES turbulence model will be described in this section. For RANS model, it only has requirements on the distance of grid vertical to the wall, as equations in the boundary layer are solved by modelling. So, the grid of RANS in the boundary layer can be anisotropic. For the LES model, since the grid scale is the filtering scale, the requirements on grid is very high and the isotropic grid needs to be designed. The DES model is solved using the RANS model in the boundary layer and the LES model in other regions. Therefore, the grid design of the DES model needs to consider the grid requirements both RANS model and the LES model synthetically.

Spalart gave the method and basic principles of grid generation for DES [36]. Fig. 3 shows the division of the calculated domain. According to the flow characteristics and grid requirements, the calculated domain can be divided into several categories: Euler region (ER), RANS model region (RANS) and LES model region (LR). The detail requirements of grid design in different regions is list in Table 3.

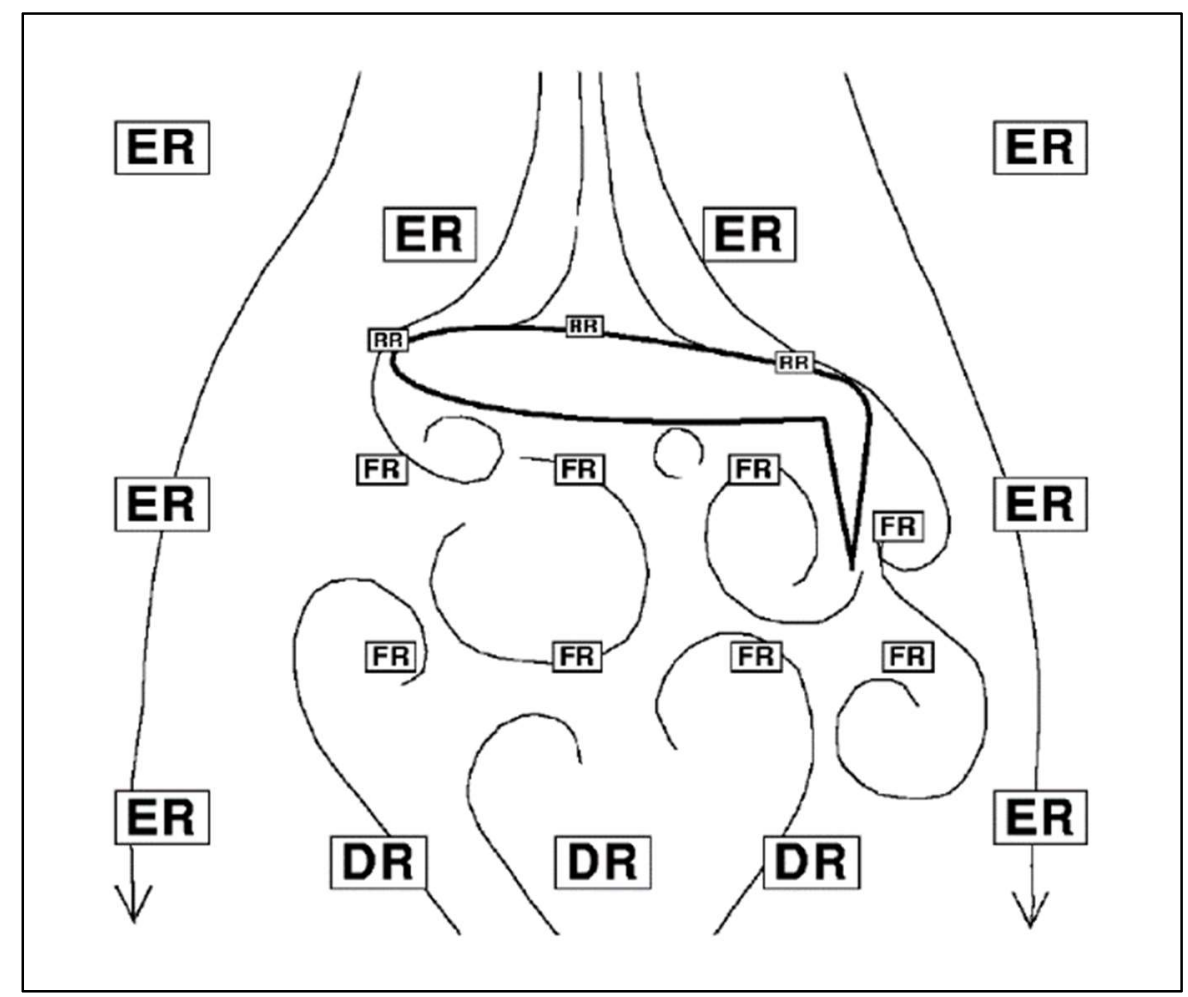

Fig. 3 The division of the calculated domain for DES model [36] 
Table 3 The detail requirements of grid design in different regions

\begin{tabular}{|c|c|c|}
\hline Region & Sub-region & Detail requirements \\
\hline $\begin{array}{l}\text { Euler Region } \\
\text { (ER) }\end{array}$ & / & $\begin{array}{l}\text { Far away from the wall and free from turbulence, less } \\
\text { demanding on meshing with the largest area. The grid } \\
\text { can be designed to be rough. }\end{array}$ \\
\hline $\begin{array}{l}\text { RANS model } \\
\text { Region (RR) }\end{array}$ & $\begin{array}{c}\text { Viscosity } \\
\text { Region (VR) }\end{array}$ & $\begin{array}{l}\text { The same requirements as RANS model, and the whole } \\
\text { boundary layer should be guaranteed to be within the } \\
\text { RANS calculation region. The requirements for y plus } \\
\text { are that } \mathrm{y}^{+}=2 \text { or less and the grid elongation generally } \\
\text { should be less than } 1.25 \text {. }\end{array}$ \\
\hline \multirow{2}{*}{$\begin{array}{l}\text { LES model } \\
\text { Region (LR) }\end{array}$} & $\begin{array}{l}\text { Focus Region } \\
\text { (FR) }\end{array}$ & $\begin{array}{l}\text { Grid resolution can be pre-set with a fixed value and the } \\
\text { grid should be isotropic (that is, the cube is best). The } \\
\text { size of Focus Region can be pre-set larger. }\end{array}$ \\
\hline & $\begin{array}{l}\text { Downstream } \\
\text { Region (DR) }\end{array}$ & $\begin{array}{l}\text { Compared with the Focus Region, the grid requirements } \\
\text { decrease, and grids can be got by enlarging the grid in } \\
\text { FR smoothly. }\end{array}$ \\
\hline
\end{tabular}

Structured grid is used and grid generation is done by using in ICEM software. Blocks and grids in different part are shown in Fig. 4 6. Most of the grids (40\%) are generated near the rotating domain to ensure the accuracy of the numerical results while reduce the calculation time-consuming.

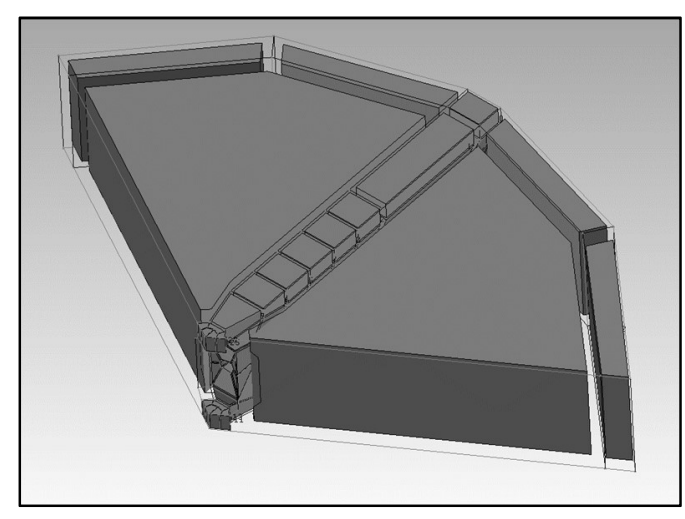

a. Blocks of rotation domain $(1 / 3)$

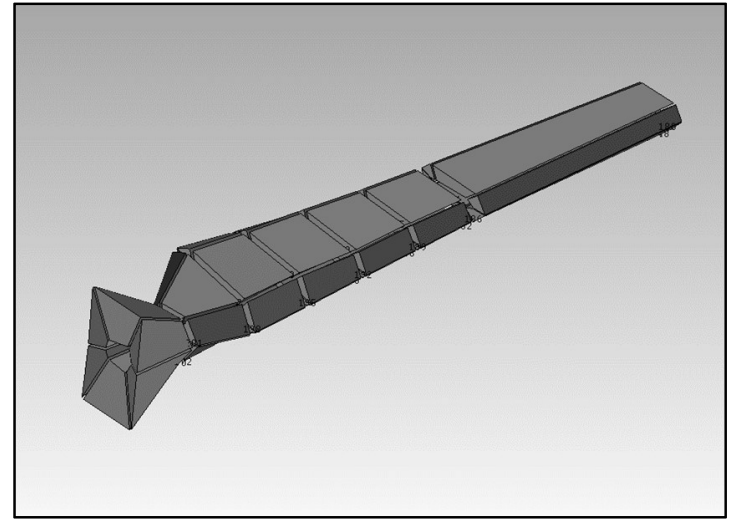

b. Blocks near the blade 


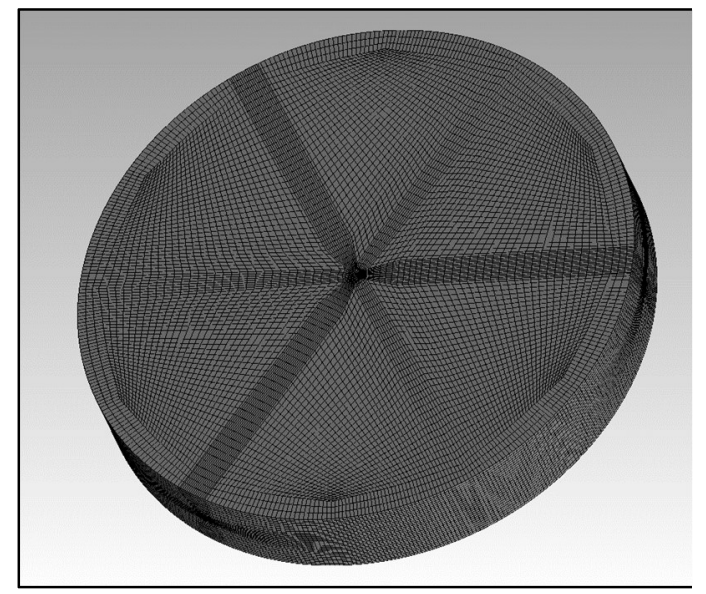

c. Grid of rotation domain

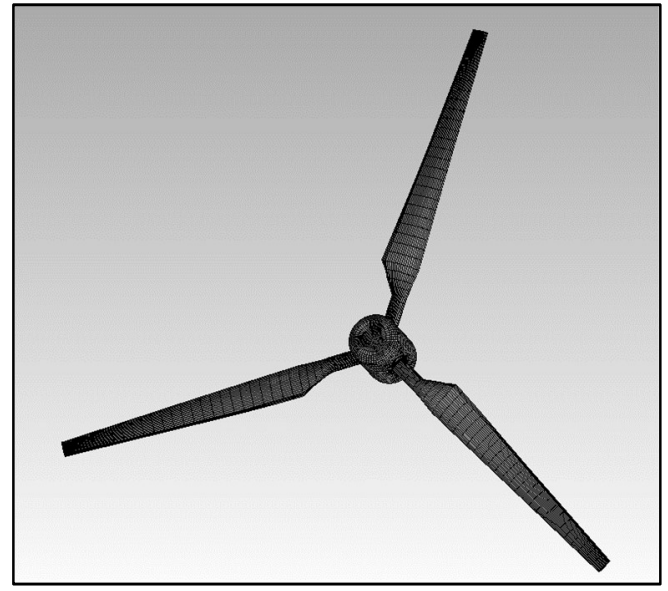

d. Grid on the surface of blade

Fig. 4 Grids creation process in rotation domain

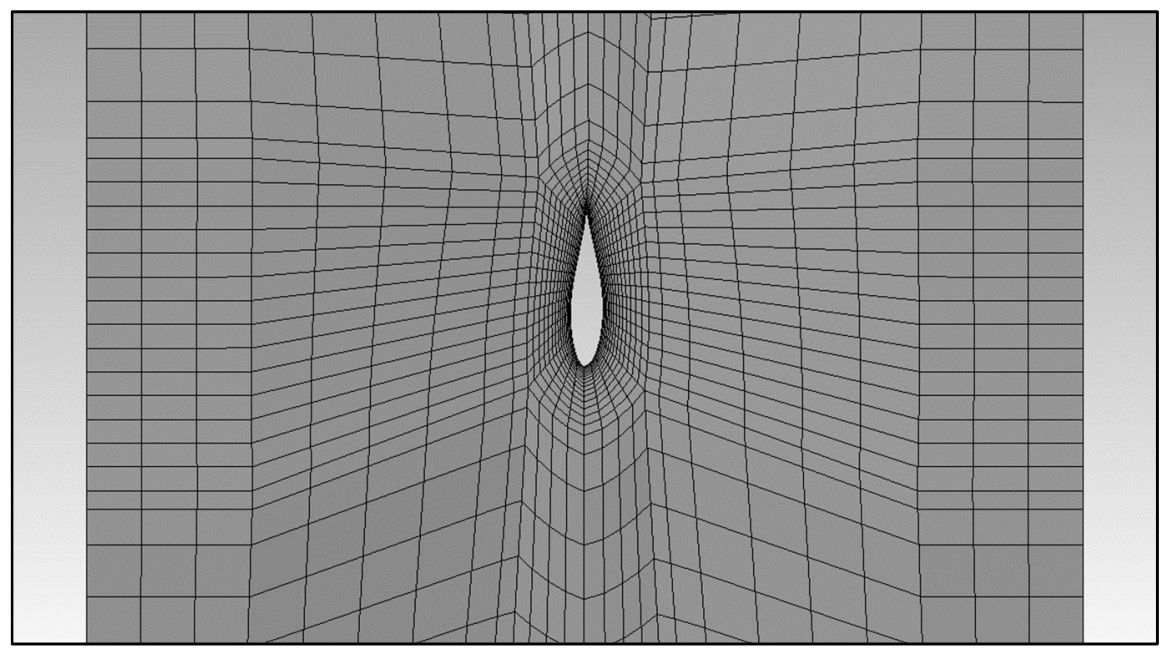

Fig. 5 Grids of boundary layer

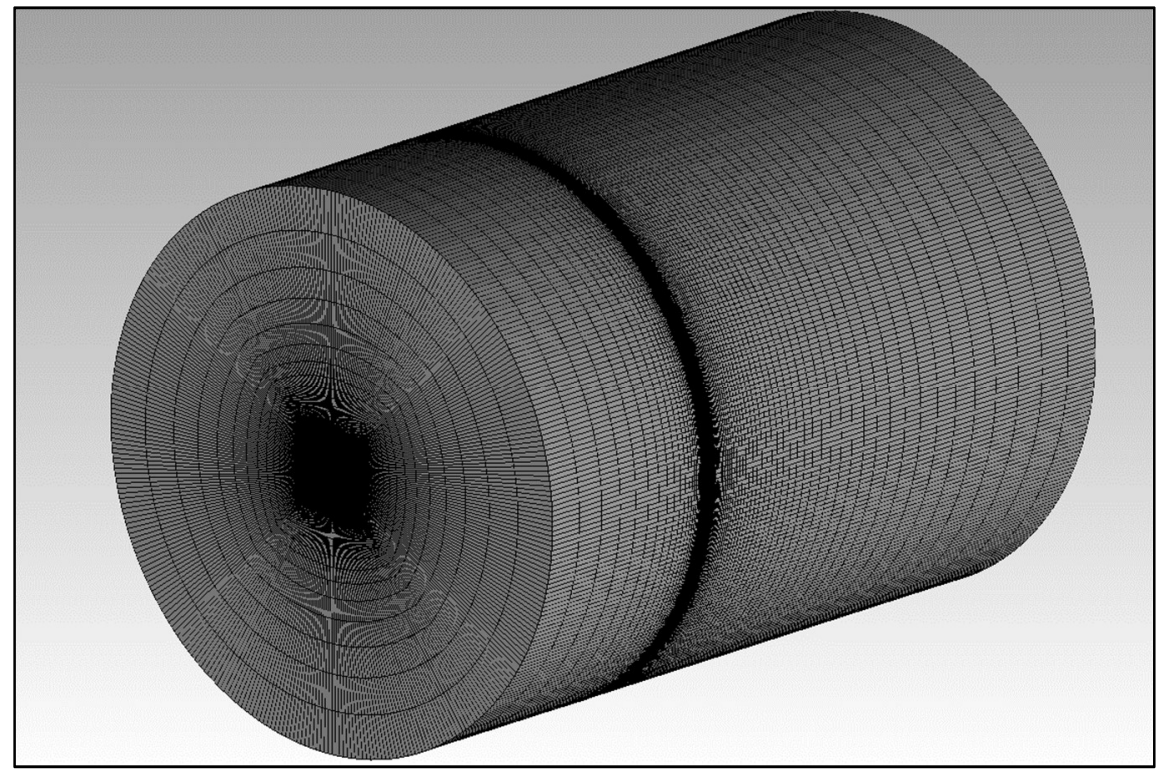

Fig. 6 Grids of the calculation domain 


\section{Validation}

This paper is a continuous work of turbine wake theory in [16] and [17]. The experimental data for the validation of numerical results is from Whale's experiment [34] which was also chosen to validate the theoretical results calculated by the proposed equations in [16]. In addition, another experimental results from Maganga [37] is also used to study the velocity distribution comparing with CFD results in this paper. A good agreement between CFD results and experimental data in predicting the efflux velocity of turbine wake was shown in [38]. The influence of turbulence model and grids on wake velocity distribution are discussed by comparing with previous experimental results.

\subsection{Influence of grid}

Grid-independent results are required when using RANS turbulence models. A grid-independent result in CFD simulation means that the simulation results do not change as the grid continues to encrypt. However, as the size of grid cell in the LES model is the filtering criterion of the vortex in the large-eddy simulation, the calculation result of the LES model is closely related to the filtration criterion of the vortex, i.e., the grid density. Therefore, it is necessary to study the effects of grid density on CFD simulation results when using DES turbulence model.

The action region of RANS in the DES model is limited in the boundary layer. After the trial calculation, as shown in Fig. 7, the y plus values on the surface of the blade calculated based on the grid are all less than 2. Thus, the boundary layer meshing meets the DES mesh design requirements.

The LES model region is very large, due to the large calculated domain. The overall number of grids would be huge, causing an expensive calculation, if the overall mesh is encrypted according to the requirements of the LES model. Therefore, the effects of the grid density are studied by changing the grid resolution in the rotation domain. In the meantime, to keep the ratio of the grids at the interfaces of each region to no more than 1.2, the grids of other regions are properly adjusted. Four cases with the grid resolution of 4.0, 3.0, 2.5 and $2.2 \mathrm{~mm}$ are carried out to study the influence of the grid density on the prediction of turbine wake, based on the DES-SA turbulence model. The tip speed ratio and solidity are set to 1.6 and 0.267 . 


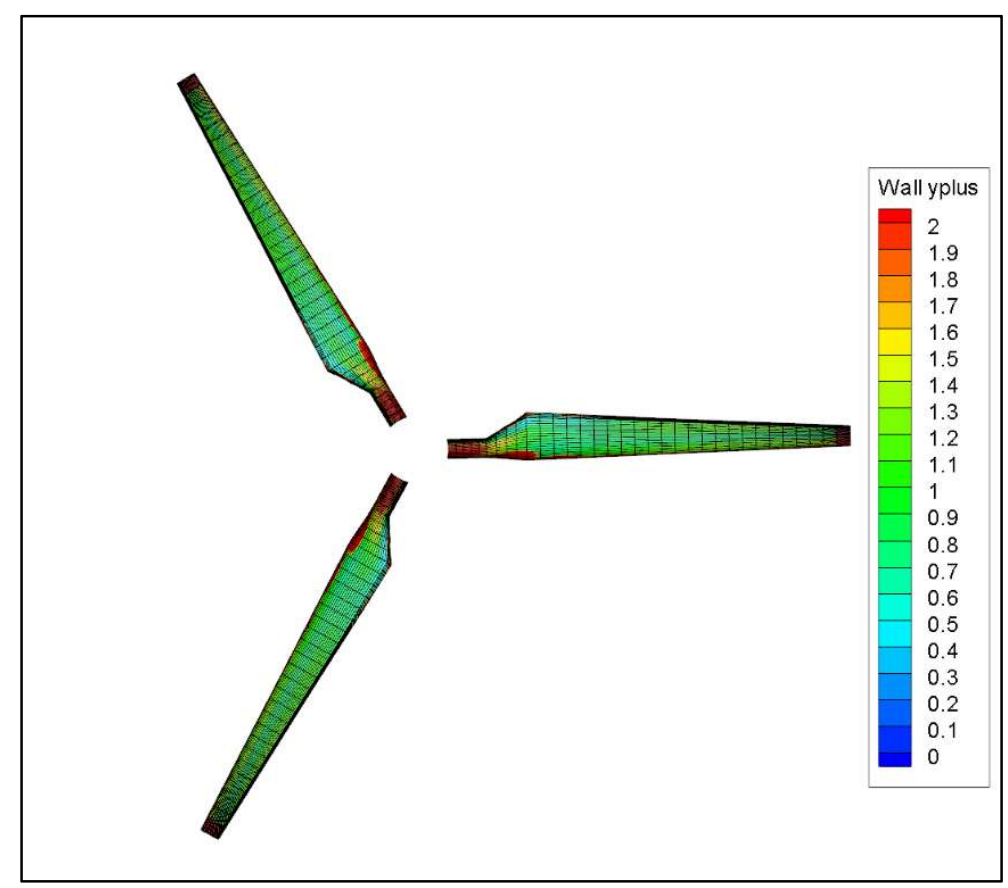

Fig. 7 The contour plot of y plus on the surface of the blade

The efflux velocities of turbine wake $(\eta=0.267, \lambda=1.6)$ with different grid resolutions are shown in Table 4. Among the four grid resolutions, the ratio of the grid number in the rotating domain to the total domain is more than $20 \%$ (the volume ratio is $0.086 \%$ ). Compared with the experimental data, the efflux velocities calculated by CFD are less than the experimental data, and the variation for all cases are less than $10 \%$. When the grid resolution decreased from 3.0 to $2.2 \mathrm{~mm}$, the number of grids increased by $27 \%$, but the calculation variation decreased by only $1.04 \%$.

Table 4 The efflux velocity with different grid densities

\begin{tabular}{cccccc}
\hline No. & Grid densities & $\begin{array}{c}\text { Number of } \\
\text { grids in } \\
\text { rotating } \\
\text { domain }\end{array}$ & $\begin{array}{c}\text { Number of } \\
\text { grids in } \\
\text { whole } \\
\text { domain }\end{array}$ & $\begin{array}{c}\text { Efflux velocity } \\
V_{0}(\mathrm{~m} / \mathrm{s})\end{array}$ & Variation $(\%)$ \\
\hline 1 & 4.0 & 247516 & 1150036 & 0.33086 & \\
2 & 3.0 & 342836 & 1635116 & 0.33098 & 9.90 \\
3 & 2.5 & 494884 & 1859434 & 0.33090 & 9.89 \\
4 & 2.2 & 573200 & 2081960 & 0.33478 & 8.83 \\
\hline
\end{tabular}

The axial velocity profiles of turbine wake with four grid resolutions are shown in Fig 8. The axial velocity distribution on the efflux plane is periodic as the turbine has 3 blades. The minimum axial velocity all occurs at the turbine rotating axis in the 4 cases, this can be referred to the effects of hub. Within the turbine disc area, the axial velocity increases from the rotating axis as the radial distance increases. The axial velocity outside the tip of blade is slightly less than the free stream velocity and is recovered to the incoming flow, which shows that the fluid outside the turbine disc is less perturbation and the radial diffusion of turbine wake is small. Compared to the 
case with a grid resolution of $4.0 \mathrm{~mm}$, the axial velocity distributions in the other 3 cases are very similar. The axial velocity distribution is more obvious as the simulation of vortex is more accurate with smaller filtering scale working in the LES model. Based on the above discussion, the subsequent calculation grid resolution will be set to $3.0 \mathrm{~mm}$ in other cases to balance the calculation accuracy and computational cost.

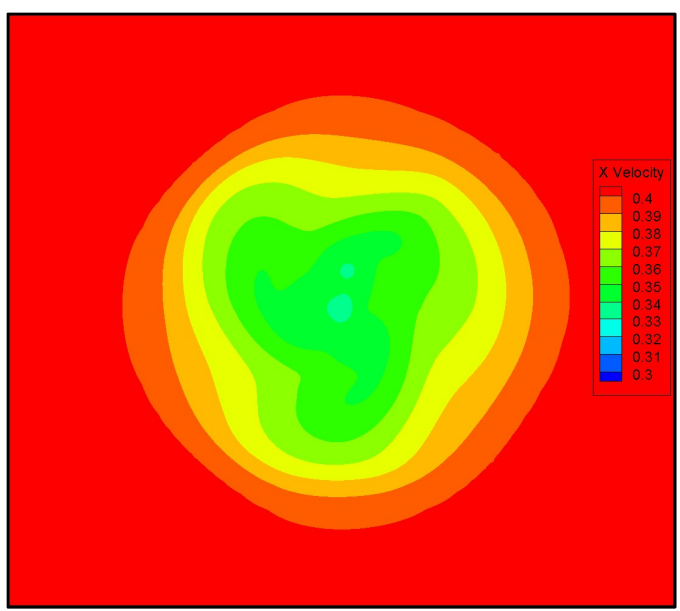

a. $\Delta_{0}=4.0 \mathrm{~mm}$

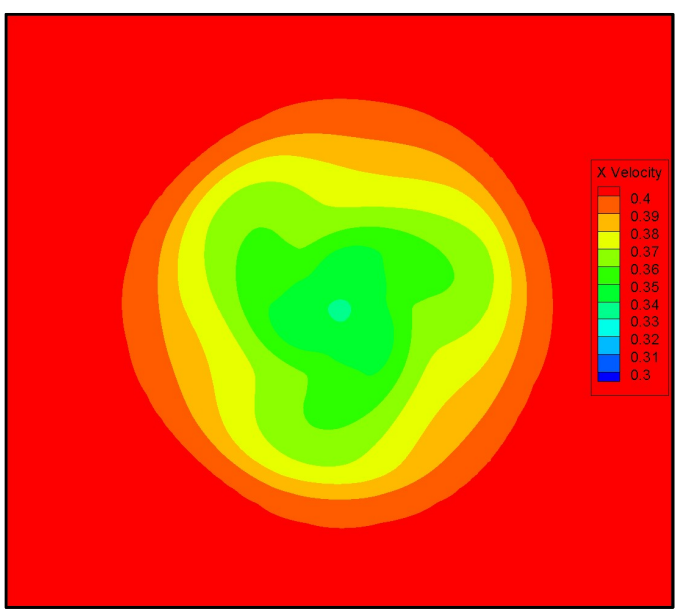

c. $\Delta_{0}=2.5 \mathrm{~mm}$

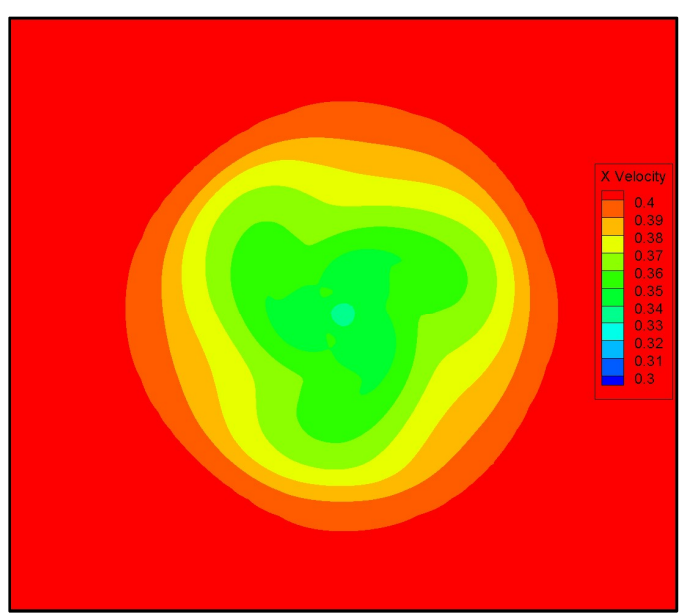

b. $\Delta_{0}=3.0 \mathrm{~mm}$

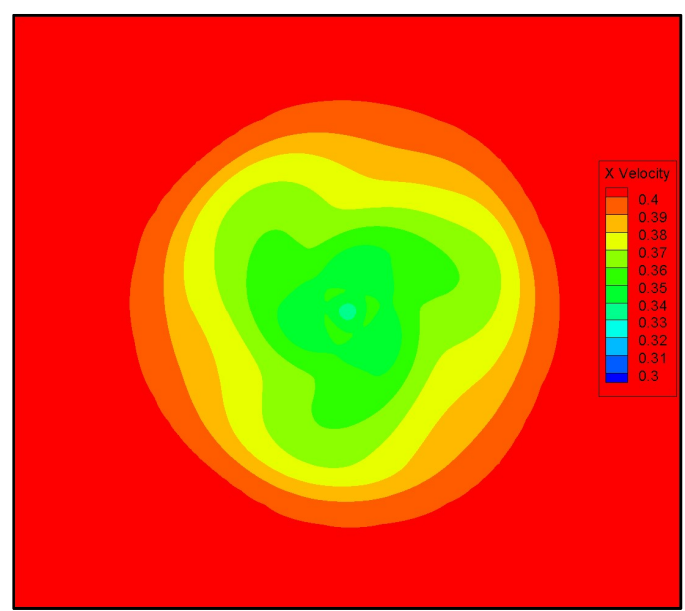

d. $\Delta_{0}=2.2 \mathrm{~mm}$

Fig. 8 The axial velocity profiles of turbine wake with four grid densities

\subsection{Influence of turbulence model}

The CFD simulation results with Spalart-Allmaras, realizable k- $\varepsilon$ and SST k- $\omega$ turbulence models and the DES model based on these three RANS models are compared in this section. Finally, a suitable turbulence model for the wake simulation of a horizontal-axis tidal-current turbine is chosen considering the calculation accuracy and calculating cost. 
The efflux velocities with different turbulence models are shown in Table $5(\eta=0.267$, $\lambda=1.6)$. Compared with the experimental data from Whale, the overall variation of RANS turbulence models is less than that of DES models. The maximum variation is $12.41 \%$ with DES-k- $\varepsilon$ turbulence model, the minimum is $2.09 \%$ with Realizable $\mathrm{k}-\varepsilon$ turbulence model, and the variation with the other four turbulence models is less than $10 \%$. In the calculating process, the DES models have longer convergence time than the RANS models. Among the three DES models, DES-SA has the fastest convergence and the highest accuracy $\left(10^{-4}\right)$. The convergence of continuity equation is difficult in DES-k- $\varepsilon$ and DES-k- $\omega$ turbulence models with an obvious fluctuation on the residual curve of continuity equation resulting in a certain degree of instability.

Table 5 The efflux velocity with different turbulence models

\begin{tabular}{ccccccc}
\hline $\begin{array}{c}\text { Turbulence } \\
\text { model }\end{array}$ & SA & $\begin{array}{c}\text { Realizable } \\
\mathrm{k}-\varepsilon\end{array}$ & $\begin{array}{c}\mathrm{SST} \\
\mathrm{k}-\omega\end{array}$ & $\mathrm{SA}$ & $\begin{array}{c}\text { DES } \\
\text { Realizable } \\
\mathrm{k}-\varepsilon\end{array}$ & $\begin{array}{c}\mathrm{SST} \\
\mathrm{k}-\omega\end{array}$ \\
\hline $\begin{array}{c}\text { Efflux } \\
\text { velocity } \\
V_{0}(\mathrm{~m} / \mathrm{s})\end{array}$ & 0.33948 & 0.35954 & 0.35606 & 0.33098 & 0.32164 & 0.35880 \\
\begin{tabular}{c} 
Variation $(\%)$ \\
\hline
\end{tabular} & 7.55 & 2.09 & 3.04 & 9.87 & 12.41 & 2.29 \\
\hline
\end{tabular}

The axial velocity profiles of turbine wake with different turbulence models are shown in Fig. 9. Compared with the RANS models, the details of the flow field on the efflux plane calculated by the DES model is more abundant. In the RANS models, the axial velocity in the SA model increases from the rotating axis with the radial distance increases. Three low-velocity zones appear at the $1 / 3$ of radius in the Realizable k- $\varepsilon$ and SST k- $\omega$ turbulence models. The axial velocity in SST k- $\omega$ model has a ring-shaped distribution of high velocity near the hub. In the corresponding DES-SA models, the axial velocity distribution on the efflux plane has more low velocity zones, whereas three low-velocity zones in the DES-SA model distribute around the rotating axis and extend toward the wake. However, the distribution of low-velocity regions in the DES-k- $\varepsilon$ and DES-k- $\omega$ turbulence model is not obvious, and there is also a ring-shaped high velocity region near the hub, but the range is larger than the SST k- $\omega$ turbulence model. The minimum axial velocities of the SA, DES-SA and DES-k- $\varepsilon$ turbulence models occur at the rotating axis and the other three turbulence models occur at the $1 / 3$ of radius. The main reason for the difference is that the DES model uses RANS model and LES model in combination, the simulation of changes of velocity is more precise as the RANS models ignore the fluctuations of wake velocity with time. Comparing the CFD simulation results, the axial velocity distribution on the efflux plane in SA and DES-SA model is more in line with Whale's experimental results. Based on the above discussion, the DES-SA turbulence model will be used in the subsequent calculation. 


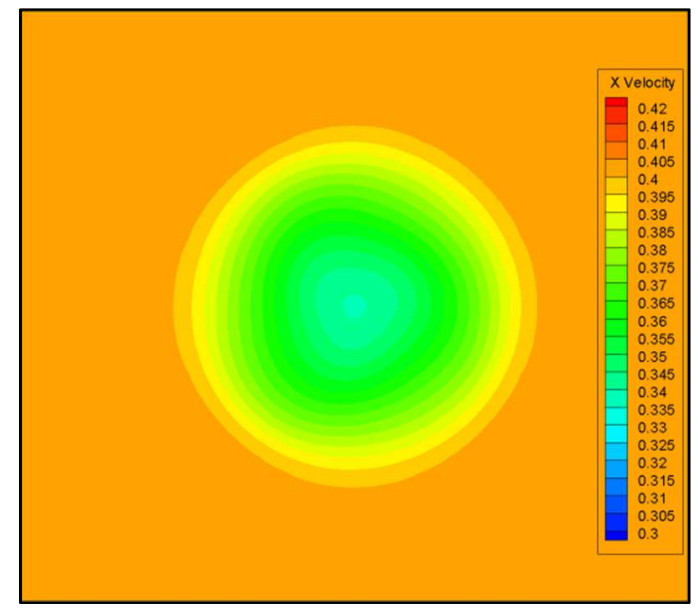

a. Spalart-Allmaras model

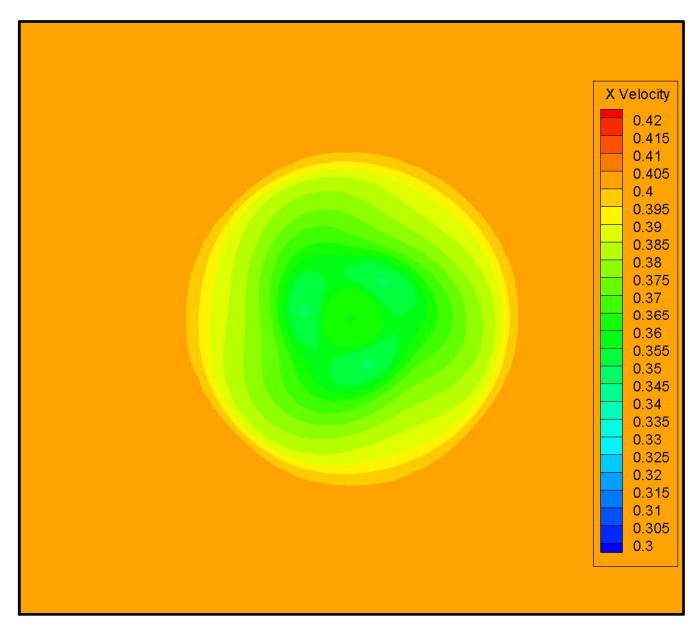

c. Realizable k- $\varepsilon$ model

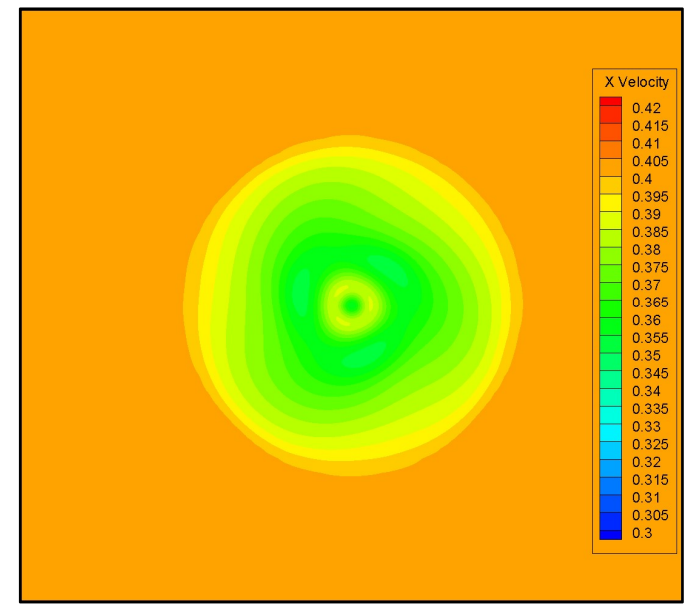

e. SST k- $\omega$ model

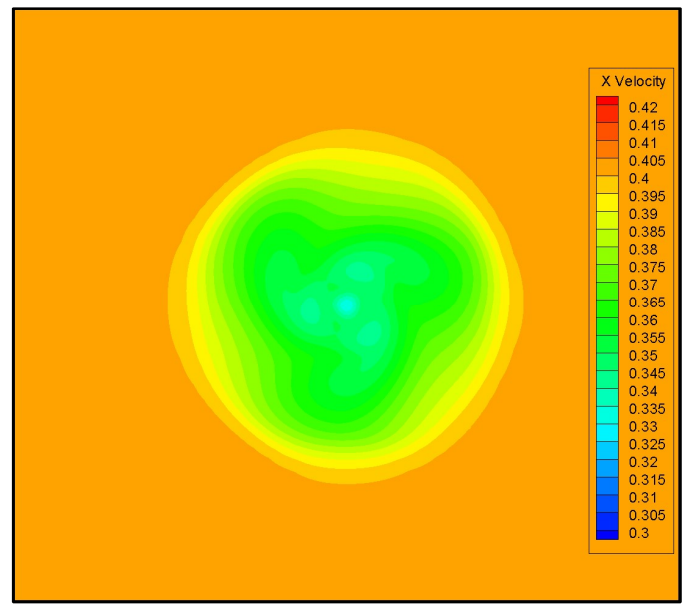

b. DES-SA model

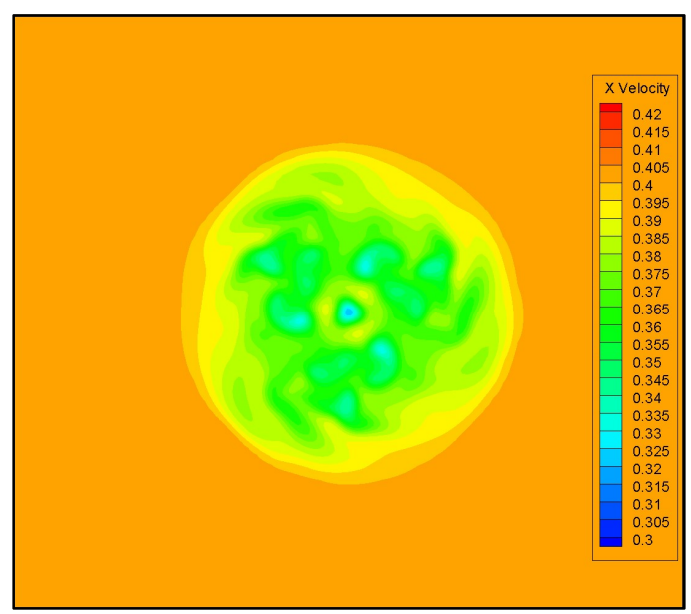

d. DES- k- $\varepsilon$ model

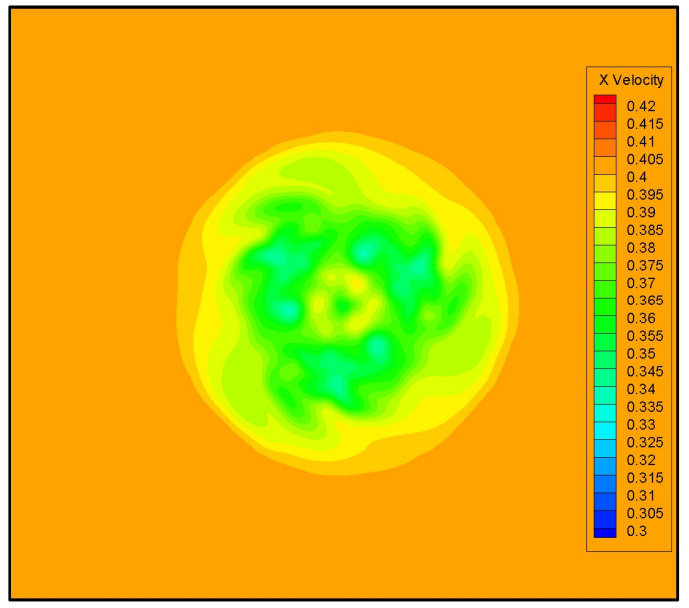

f. DES- k- $\omega$ model

Fig. 9 The axial velocity profiles of turbine wake with different turbulence models 


\section{Results and discussion}

The effects of TSR and solidity on the efflux velocity based on these CFD simulation are introduced in Ref. [38]. In this paper, the velocity distribution of axial, tangential and radial velocity component of turbine wake is analysed by comparing the numerical results with experimental and theoretical results. Finally, a semi-empirical wake structure is given to improve the predicted profile of turbine wake proposed by Lam.

CFD results with 3 blades and different TSR corresponding to Whale's experimental model are chosen to study the wake velocity distribution by comparing with experimental results. Maganga's experiments about turbine wake [37] and Lam's experiments about the propeller jet [39] are also chosen to be a supplementary comparison since the theoretical method of turbine wake is also referred to propeller.

\subsection{Axial velocity}

The axial velocity is the most important velocity component of turbine wake. The axial velocity distribution is analysed from the following aspects: the efflux velocity, the division of zone of establishment flow and zone of flow established and the axial velocity distribution.

\subsubsection{Efflux velocity}

The efflux velocity of horizontal axis turbine is the base for the analysis of turbine wake. The efflux velocity equation for tidal turbine wake are shown in Table 6 . The efflux equation Eq. (6) is proposed to improve the accuracy of theoretical equation Eq. (5) based on the simulation results using the DES-SA turbulence model. The coefficient 1.39 in Eq. (6) is less than that 1.59 in Eq. (5), which means that the measured value of efflux velocity using DES-SA model is lower than the theoretical value of axial momentum theory. This may be due to the different choice of the efflux velocity of turbine wake. The axial momentum theory assumed "all elements of fluid passing through the disc undergo an equal increase of pressure", which implying an average velocity at the efflux plane was taken as efflux velocity rather than the minimum velocity

Table 6 The efflux velocity equation of turbine wake

\begin{tabular}{cccc}
\hline Type & Researcher & Equation & No. \\
\hline \multirow{2}{*}{ Tidal turbine } & Lam-Chen & $V_{0}=\sqrt{\left(V_{\infty}\right)^{2}-\left(1.59 n D \sqrt{C_{t}}\right)^{2}}$ & (5) \\
\cline { 2 - 4 } & Lam-Wang & $V_{0}=\sqrt{\left(V_{\infty}\right)^{2}-\left(1.39 n D \sqrt{C_{t}}\right)^{2}}$ \\
\hline
\end{tabular}

\subsubsection{Zone of flow establishment and established flow}

Previous analysis shows that after the fluid flows through the turbine, the wake velocity is less than the free stream velocity as the energy is extracted by tidal turbine. Assuming the absence of external interference, the flow of fluid meets the Bernoulli 
equation. The velocity distribution is uneven, causing the mixing of fluids behind the turbine with each other. The mixing of the fluids causes the wake to redistribute finally. Similar to the research of propeller jet [40], the turbine wake can be divided into the zone of flow establishment and zone of established flow. The zone of flow establishment can be defined as the lateral velocity distribution of the axial velocity changes from two velocity valleys (one side by one) to one occurring at rotating axis along the radial direction, the position of the minimum axial velocity finally appears at the rotating axis as the turbine wake fully developed.

The values and locations of the non-dimensional axial velocity at different cross-sections $(x / D=0.5,1.0,1.5,2.0,2.5)$ with different tip speed ratio $(\lambda=1.6,2.7$, 3.2) are shown in Table 7-9. The velocity variation between numerical and experimental results is also compared. CFD results show that the minimum axial velocity at each cross section increases gradually with the wake develops downstream, and the position finally appears at the rotating axis of turbine, which is the same as that of Whale and Maganga's experimental results. Wherein, the position of the minimum dimensionless axial velocity $r / R$ decreases to 0 at cross section $x / D=$ 1.5 when tip speed ratio $\lambda=1.6$, at cross section $x / D=2.0$ when tip speed ratio $\lambda=$ 2.7 , and at cross section $x / D=2.5$ when tip speed ratio $\lambda=3.2$. From this, it can be estimated that the length of the zone of flow establishment for the horizontal-axis tidal-current turbine used in this paper is $1.5 \mathrm{D}, 2.0 \mathrm{D}$ and $2.5 \mathrm{D}$ at three kinds of tip speed ratios respectively. Due to the hub of turbine is connected to the fixing device in Whale's experiments, the axial velocity around the hub fluctuates greatly, and the position of the minimum dimensionless axial velocity develops no obvious rule from the wake to the downstream. When $\lambda=1.6$, the position occurs as far as $r / R=0.34$, and the position is close to the axis of rotation when $\lambda=2.7,3.2$.

Table 7 The values and locations of the non-dimensional axial velocity at different cross-sections with $\lambda=1.6$

\begin{tabular}{|c|c|c|c|c|c|}
\hline \multirow{3}{*}{$x / D$} & \multicolumn{2}{|c|}{ The minimum axial velocity } & \multicolumn{2}{|c|}{ Position $(r / R)$} & \multirow{3}{*}{ Variation $(\%)$} \\
\hline & \multicolumn{2}{|c|}{$\left(V_{a} / V_{\infty}\right)$} & & & \\
\hline & Experiment & CFD & Experiment & CFD & \\
\hline 0.5 & 0.91 & 0.77 & 0.34 & 0.23 & 15.38 \\
\hline 1.0 & 0.86 & 0.85 & 0.06 & 0.22 & 1.16 \\
\hline 1.5 & 0.85 & 0.86 & 0.33 & 0 & 1.18 \\
\hline 2.0 & 0.88 & 0.95 & 0.05 & 0 & 7.95 \\
\hline 2.5 & 0.90 & 0.94 & 0 & 0 & 4.44 \\
\hline
\end{tabular}


Table 8 The values and locations of the non-dimensional axial velocity at different cross-sections with $\lambda=2.7$

\begin{tabular}{cccccc}
\hline & The minimum axial velocity & Position $(r / R)$ & \\
$x / D$ & \multicolumn{2}{c}{$\left(V_{a} / V_{\infty}\right)$} & & Variation (\%) \\
& Experiment & CFD & Experiment & CFD & \\
\hline 0.5 & 0.83 & 0.76 & 0 & 0.23 & 8.43 \\
1.0 & 0.80 & 0.80 & 0 & 0.24 & 0.00 \\
1.5 & 0.83 & 0.83 & 0.05 & 0.24 & 0.00 \\
2.0 & 0.88 & 0.93 & 0 & 0 & 5.68 \\
2.5 & 0.90 & 0.89 & 0 & 0 & 1.11 \\
\hline
\end{tabular}

Table 9 The values and locations of the non-dimensional axial velocity at different cross-sections

\begin{tabular}{cccccc}
\multicolumn{5}{c}{ with $\lambda=3.2$} \\
$x / D$ & The minimum axial velocity & Position $(r / R)$ & Variation (\%) \\
& Experiment & CFD & Experiment & CFD & \\
\hline 0.5 & 0.80 & 0.77 & 0 & 0.25 & 3.75 \\
1.0 & 0.73 & 0.79 & 0 & 0.26 & 8.22 \\
1.5 & 0.82 & 0.82 & 0 & 0.26 & 0.00 \\
2.0 & 0.79 & 0.91 & 0.06 & 0.13 & 15.19 \\
2.5 & 0.79 & 0.87 & 0 & 0 & 10.13 \\
\hline
\end{tabular}

CFD results show that the length of zone of flow establishment increases with the increase of tip speed ratio of turbine. When the tip speed ratio increases from 1.6 to 3.2 , the length increases from $1.5 \mathrm{D}$ to $2.5 \mathrm{D}$. In Maganga's experiment, the length is $5 \mathrm{D}$ with the tip speed ratio $\lambda=18$. The length of zone of flow establishment for turbine is less than that of Albertson (6.2D), and close to the length of Propeller (3.68D) measured by Lam based on LDA experiment [34]. This can be referred to the smaller rotating speed and distortion of tidal turbine, which causes less changing of fluid. 


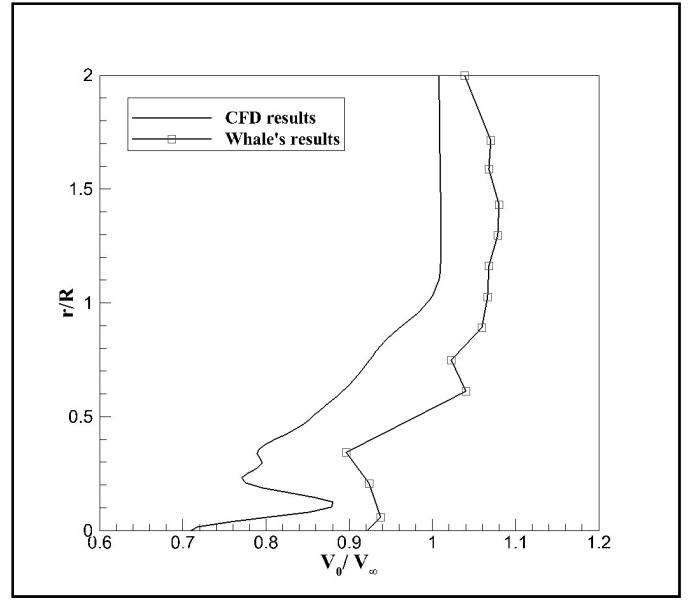

a. $x / D=0.5$

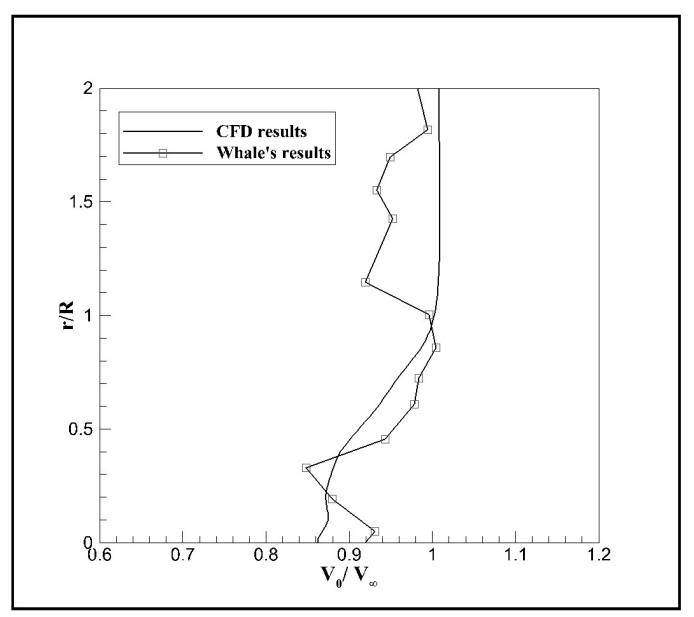

c. $x / D=1.5$

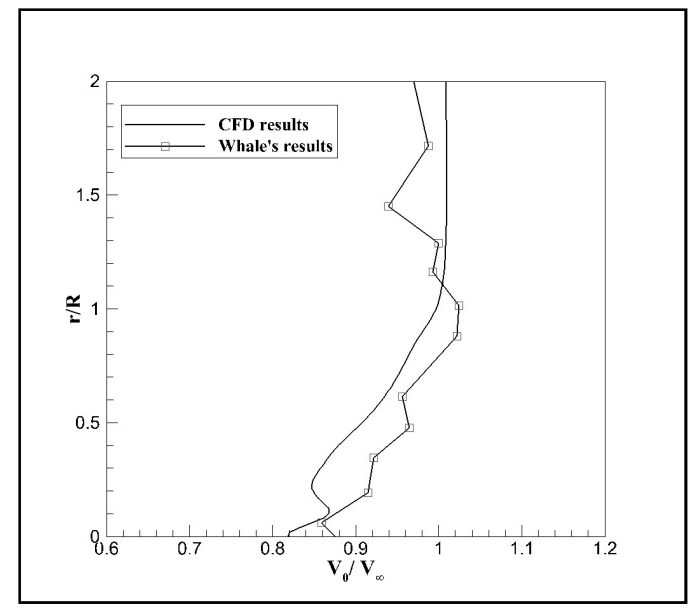

b. $x / D=1.0$

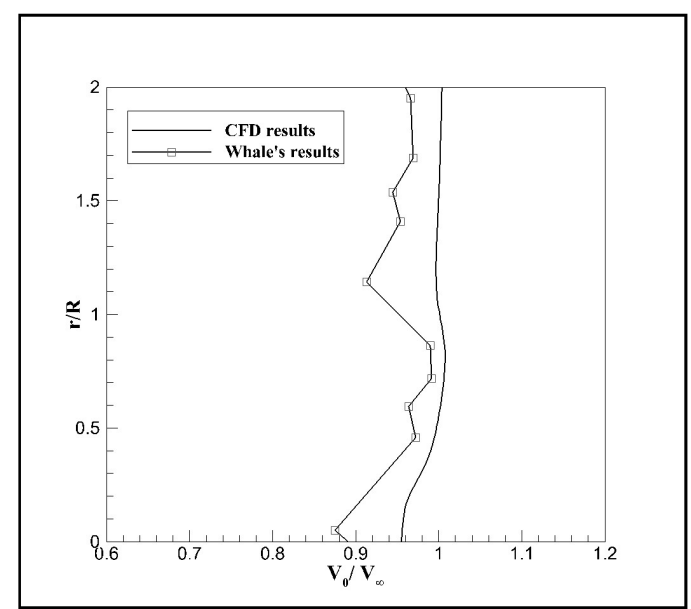

d. $x / D=2.0$

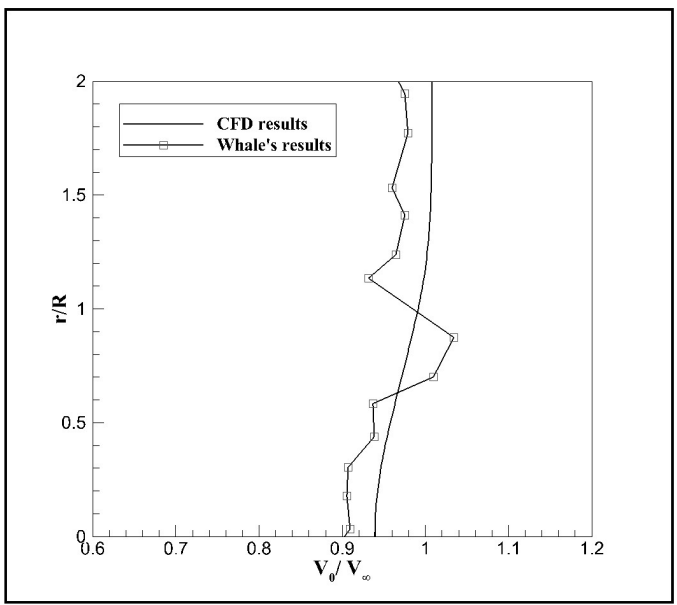

e. $x / D=2.5$

Fig. 10 The non-dimensional axial velocity distribution at different cross-sections with $\lambda=1.6$ 


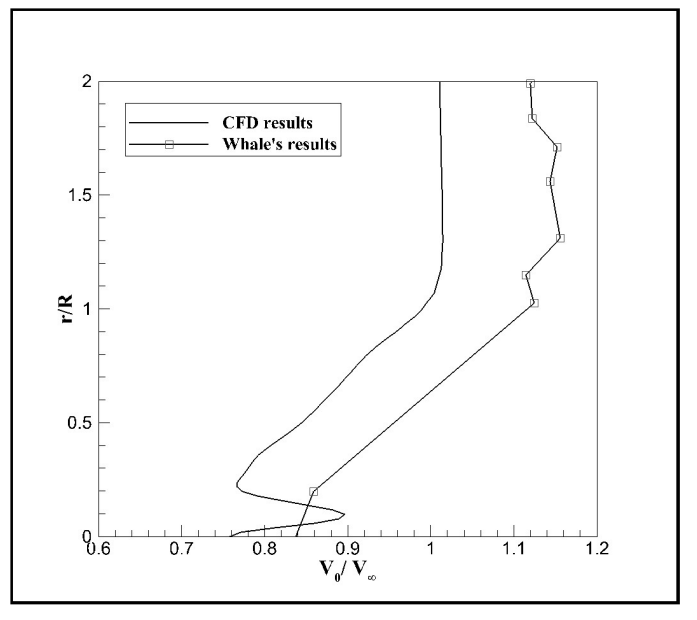

a. $x / D=0.5$

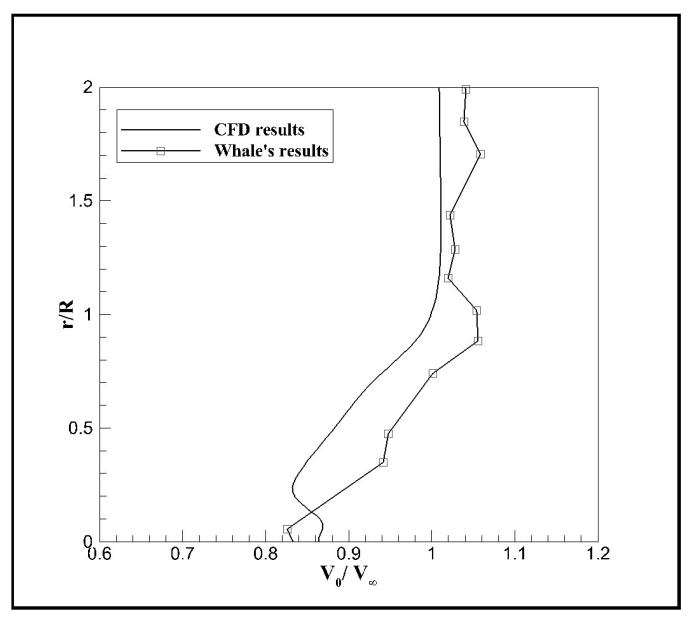

c. $x / D=1.5$

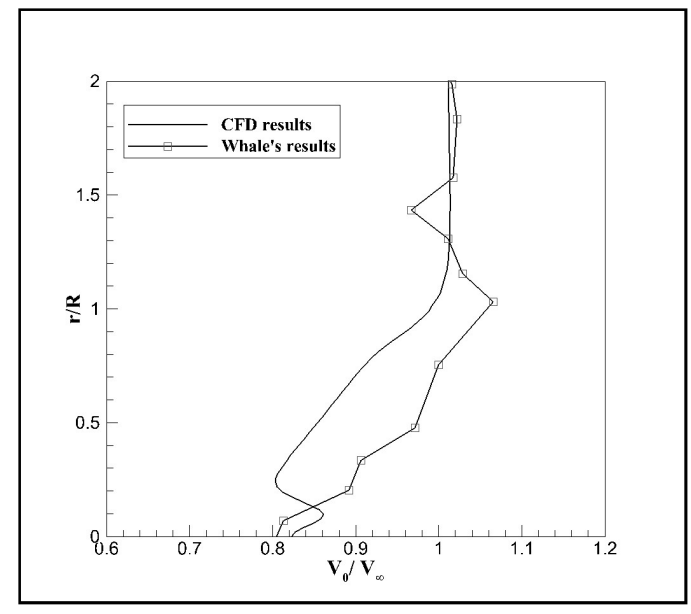

b. $x / D=1.0$

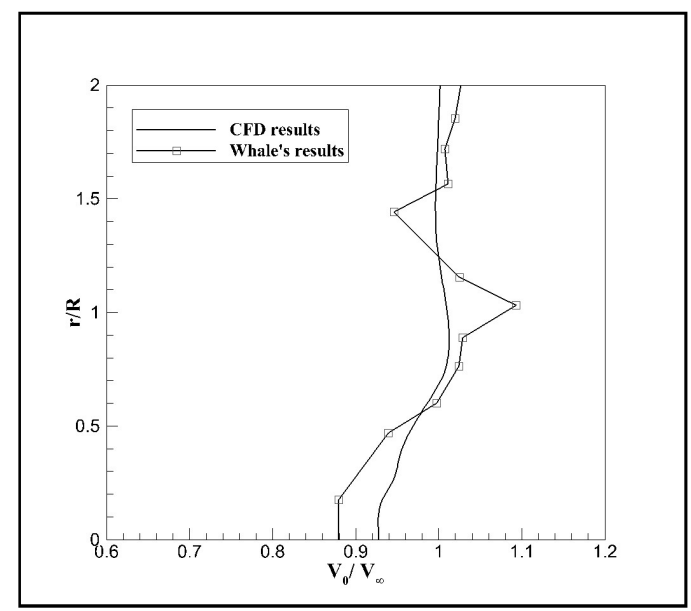

d. $x / D=2.0$

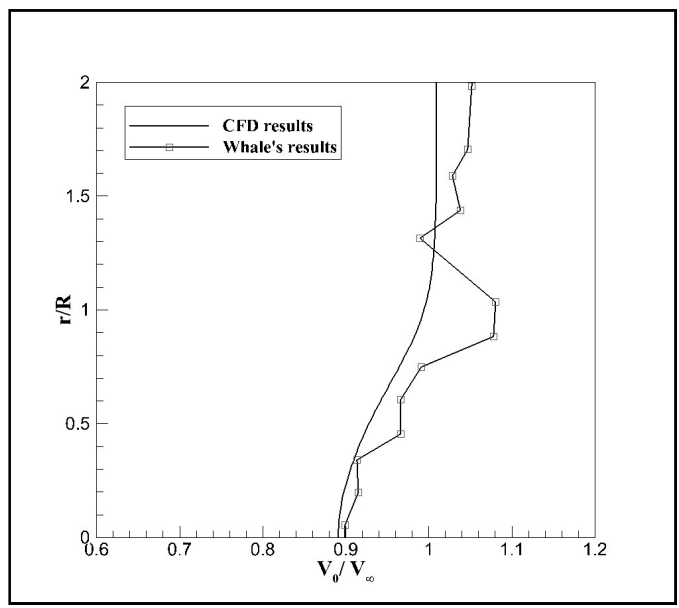

e. $x / D=2.5$

Fig. 11 The non-dimensional axial velocity distribution at different cross-sections with $\lambda=2.7$ 


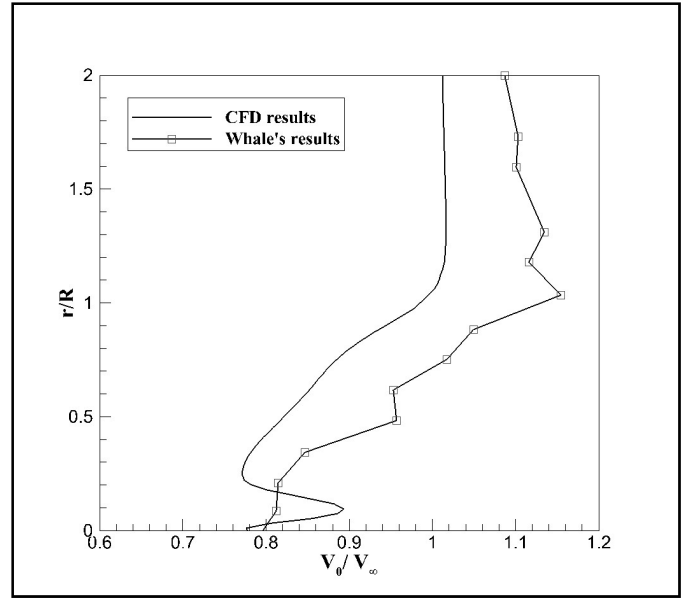

a. $x / D=0.5$

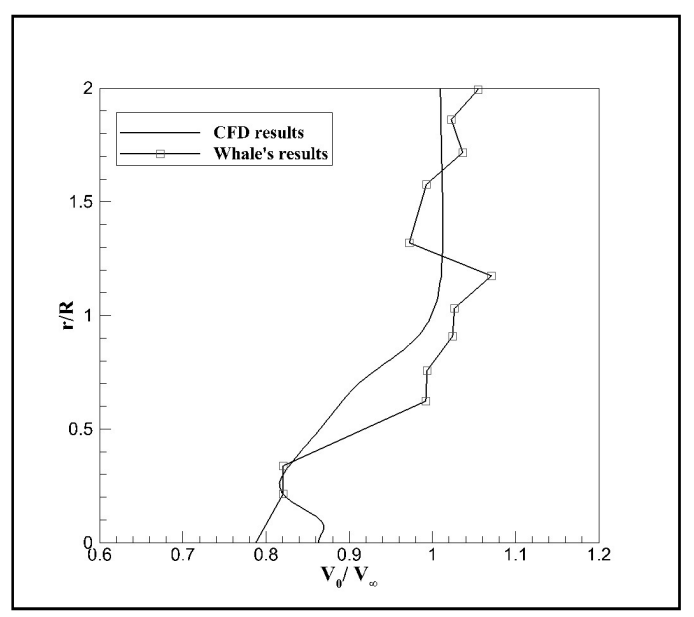

c. $x / D=1.5$

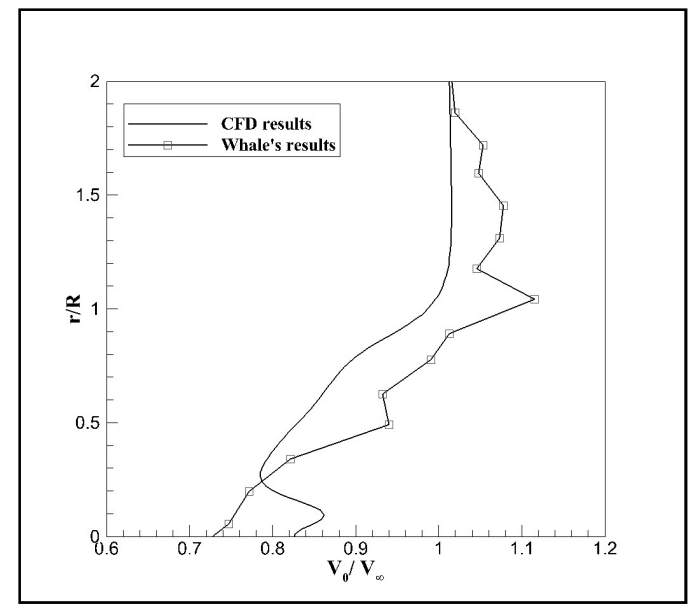

b. $x / D=1.0$

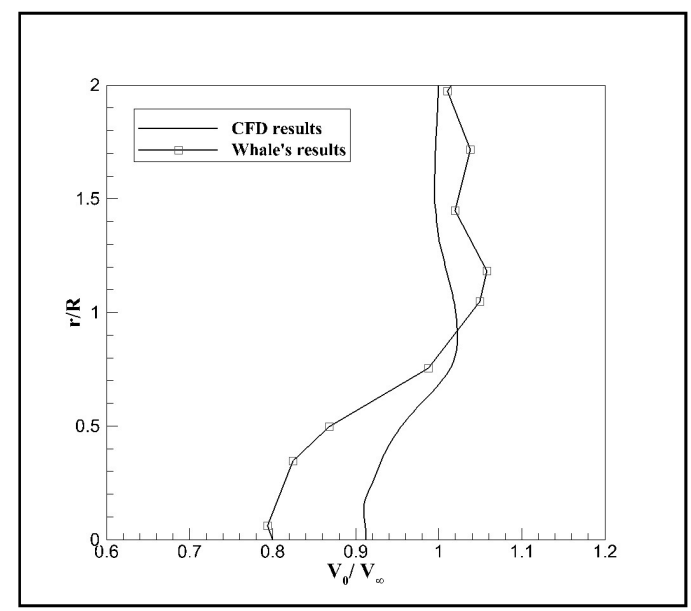

d. $x / D=2.0$

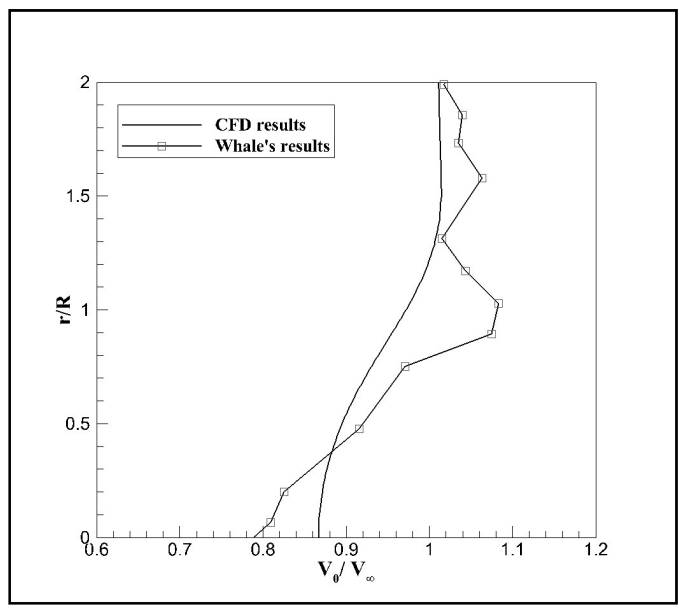

e. $x / D=2.5$

Fig. 12 The non-dimensional axial velocity distribution at different cross-sections with $\lambda=3.2$ 


\subsubsection{Axial velocity distribution in the zone of flow establishment}

The non-dimensional axial velocity distribution at different cross-sections with different tip speed ratio $(\lambda=1.6,2.7,3.2)$ are compared in Fig. 10-12. According to the definition of the zone of flow establishment, there are two velocity valleys occurring along the lateral velocity distribution (one on each side of the rotating axis). The position where the valley velocities occur is the position of the minimum axis velocity.

\subsubsection{Position of the minimum axial velocity}

As shown in Fig. 10-12, the position of the minimum axial velocity of turbine wake remains constant with a constant tip speed ratio in the zone of flow establishment. As the tip speed ratio increases, the position is offset radially to the tip of blade. In this paper, the position of the minimum axial velocity generated by $\lambda=1.6,2.7,3.2$ are $r / R=0.22,0.24,0.26$, respectively. The position got by Maganga's experiment is $r / R=0.88$ with $\lambda=18$ [33], which is larger than that got by CFD results in this paper. The difference between the Maganga's experimental results and CFD results is due to the effect of the tip speed ratio and the different turbine blade geometry used.

\subsubsection{Recovery of the minimum axial velocity}

As shown in Table 7-9, the CFD simulation results are in good agreement with the Whale's experimental results for the prediction of the minimum dimensionless axial velocity at different cross-sections in the wake flow field of a horizontal-axis turbine. The variation between the CFD prediction and the experimental measurement is between $0.00 \%$ and $15.38 \%$, and the maximum variation occurs at $r / R=0.5$ with the tip speed ratio $\lambda=1.6$. Within the zone of flow establishment, the minimum axial velocity gradually increases with the axial distance increases from the rotating axis of turbine. The minimum axial velocity increases from 0.77 to 0.86 when $\lambda=1.6,0.76$ to 0.93 when $\lambda=2.7$ and 0.77 to 0.87 when $\lambda=3.2$. In the Maganga's experiment, the minimum axial velocity was recovered to 0.63 times of the free stream velocity, and in the Whale's experiment was recovered to 0.79 times. Compared with the Whale's experiment, the wake recovery was more pronounced with CFD results, which was mainly due to the difference of hub of tidal turbine. In the setup of Whale's experiment, the hub was attached to the fixture, which indirectly corresponded to the lengthening of hub. The interference of the hub with turbine wake intensifies, resulting in a low velocity at the rotating axis and a small degree of wake recovery. The difference of wake recovery between CFD results and Maganga's experiment is mainly refer to the different tip speed ratio.

The recovery of axial velocity of turbine wake is due to the exchange of energy and momentum between the fluid in the turbine disc and the surrounding free fluid. At the stream tube boundary, the fluid in both sides mix with each other causing the velocity of the fluid inside the boundary to increase, as the axial velocity of fluid inside is less than that of the external free stream. Similarly, the exchange of energy and momentum is also taken place between the fluid with increased velocity inside the boundary and the inner fluid close to the rotating axis. The mixing of fluid inside the turbine disc model finally results in an overall increase of the axial velocity of turbine 
wake. The axial distribution equations of axial velocity for a horizontal-axis turbine in the zone of flow establishment are shown in Table 10. Lam proposed that the recovery of the minimum dimensionless axial velocity in the axial direction is linear with the non-dimensional distance from the axis of the turbine and gave the recovery equation Eq. (7). The recovery equation Eq. (8) is proposed using the simulation results with the DES-SA turbulence model and it shows that the velocity recovery speed along axial direction is faster than Lam's results.

Table 10 The axial distribution equation of axial velocities for horizontal-axis turbine in the zone of flow establishment

\begin{tabular}{cccc}
\hline Type & Researcher & Equation & No. \\
\hline \multirow{2}{*}{ Tidal turbine } & Lam & $0<x \leq 4 D: \frac{V_{\min }}{V_{0}}=0.0106\left(\frac{x}{D}\right)+1.0351$ & (7) \\
\cline { 2 - 4 } & Lam-Wang & $\frac{V_{\min }}{V_{0}}=0.0509\left(\frac{x}{D}\right)+0.742$ & (8) \\
\hline
\end{tabular}

\subsubsection{Lateral velocity distribution of axial velocity}

The radial distribution of the axial velocity in the zone of flow establishment is shown in Fig. 10-12. The axial velocity of turbine wake increases firstly and then decreases in the radial direction from the rotating axis, that is, the radial velocity distribution of the axial velocity shows two velocity valleys (a velocity valley on each side), the position of valley is the position of the minimum axial velocity. As described in Section 4.1.3.1 and 4.1.3.2, the dimensionless distance of the valley velocity (the minimum axial velocity) from the rotating axis remains unchanged, but the dimensionless valley velocity gradually increases with the turbine wake developed, and finally the axial velocity distribution within the turbine disc tends to be gentle. The trend of axial velocity distribution at each section obtained by Whale experiment is consistent with numerical results.

Outside the turbine disc, CFD results show that the dimensionless axial velocity varies little in the radial direction and the axial velocity approaches the free stream velocity. It means that the fluid outside the turbine disc is less disturbed by the rotating turbine. As shown in Whale experimental results, the radial velocity distribution curve of the axial velocity fluctuates greatly in this region, and this may be due to the smaller flume used in this experiment. The flume width is only $0.4 \mathrm{~m}$ (the blade diameter is $0.2 \mathrm{~m}$ ), leading to the area outside the disc is near the wall sink and is greatly disturbed by the wall. The larger axial velocity at the tip of blade ( $r / R=1)$ may be the effect of blade tip disturbance. The radial distribution equations of axial velocity for turbine wake in the zone of flow establishment are shown in Table 11. Considering the velocity deficit occurred behind the turbine, Lam proposed the Eq. (9) based on the Gaussian probability distribution. Similarly, for the WM19S turbine, Eq. (10) is proposed to correct the Eq. (9) using the numerical results with the DES-SA turbulence model. 
Table 11 The radial distribution equation of axial velocities for horizontal-axis turbine in the zone of flow establishment

\begin{tabular}{|c|c|c|c|}
\hline Type & Researcher & Equation & No. \\
\hline \multirow{2}{*}{$\begin{array}{c}\text { Tidal } \\
\text { turbine }\end{array}$} & Lam & $\begin{array}{l}V_{x, r}=V_{\infty}-\left(V_{\infty}-V_{\min }\right) e^{A} \\
x \leq 0.5 D: A=\left[-0.5\left(\left(r-R_{m 0}\right) /\left(\frac{R_{m 0}}{2}\right)\right)^{2}\right] \\
0.5 D<x \leq 3.0 D: A=\left[-0.5\left(\left(r-R_{m 0}\right) /\left(\left(\frac{R_{m 0}}{2}\right)-0.075(x-R)\right)\right.\right.\end{array}$ & (9) \\
\hline & Lam-Wang & $\begin{array}{l}V_{x, r}=V_{\infty}-\left(V_{\infty}-V_{\min }\right) e^{A} \\
x \leq 0.5 D: A=\left[-0.07\left(\left(r-R_{m 0}\right) /\left(\frac{R_{m 0}}{2}\right)\right)^{2}\right] \\
0.5 D<x \leq 2.5 D: A=\left[-0.07\left(\left(r-R_{m 0}\right) /\left(\left(\frac{R_{m 0}}{2}\right)-0.204(x-R)\right)\right.\right.\end{array}$ & (10) \\
\hline
\end{tabular}

\subsubsection{Axial velocity distribution in the zone of established flow}

In the zone of established flow, the fluid is far away from the turbine and is mainly exchanging energy and momentum with the surrounding stationary fluid. In this section, the numerical results at tip speed ratio $\lambda=1.6$ are used to analyse the axial recovery of the minimum axial velocity and the radial distribution of axial velocity.

\subsubsection{Position of the minimum axial velocity}

According to the definition of the zone of established flow, the minimum axial velocity of wake occurs on the rotating axis of turbine. The influence of the blade hub on the turbine wake distribution is weakened. As the axial distance from the rotating axis increases, the position of the minimum axial velocity remains constant.

\subsubsection{Recovery of the minimum axial velocity}

The minimum axial velocity gradually increases as the wake developed, eventually reaching the rate of the incoming flow in the zone of established flow. As shown in Table 7, CFD results show that the minimum dimensionless axial velocity $V_{a} / V_{\infty}$ gradually recovers from 0.86 to 0.94 when the axial distance $x / D$ from 1.5 to 2.5 with tip speed ratio $\lambda=1.6$. Whale experimental measurements show that the minimum dimensionless axial velocity is gradually recovered from 0.85 to 0.90 , that is, $90 \%$ of the initial velocity is recovered. Table 12 shows the axial distribution equations of axial velocity for turbine wake in the zone of established flow. Lam proposed an empirical equation Eq. (11), implying that the recovery rate in the zone of flow establishment is much faster than that in the zone of established flow. The empirical equation Eq. (12) is the same to Eq. (8), as the recovery of wake in the zone of established flow cannot be completely simulated, due to the short calculation range in this paper. 
Table 12 The axial distribution equation of axial velocities for horizontal-axis turbine in the zone of established flow

\begin{tabular}{cccc}
\hline Type & Researcher & Equation & No. \\
\hline \multirow{2}{*}{ Tidal turbine } & Lam & $x>4 D: \frac{V_{\min }}{V_{0}}=0.1123\left(\frac{x}{D}\right)+0.5826$ & (11) \\
\cline { 2 - 4 } & Lam-Wang & $\frac{V_{\min }}{V_{0}}=0.0509\left(\frac{x}{D}\right)+0.742$ & (12) \\
\hline
\end{tabular}

\subsubsection{Lateral velocity distribution of axial velocity}

In the zone of established flow, the axial velocity gradually increases from the minimum axial velocity to the incoming velocity in the radial direction. The radial distribution curve of the axial velocity only shows a valley at the rotating axis. As shown in Fig. 10-12, the distribution curve tends to be gentle as the axial distance increases. When the minimum axial velocity gradually returns to the magnitude of the incoming flow, the wake flow field of the turbine is recovered to the incoming flow field and the turbine wake disappears. For the prediction of the lateral velocity distribution in the zone of flow established, CFD results are consistent with the wake prediction model proposed by Lam [17]. Table 13 shows the radial distribution equations of axial velocity for turbine wake in the zone of established flow. Lam stated that the influence of the hub was limited to the zone of flow establishment, the turbine wake in the zone of established flow only affected by the surrounding fluid. Similarly, Eq. (14) is proposed to describe the radial distribution of axial velocity based on the Eq. (13) using the numerical results with the DES-SA turbulence model.

Table 13 The radial distribution equation of axial velocities for horizontal-axis turbine in the zone of established flow

\begin{tabular}{|c|c|c|c|}
\hline Type & Researcher & Equation & No. \\
\hline \multirow{2}{*}{ Tidal turbine } & Lam & $\begin{array}{l}V_{x, r}=V_{\infty}-\left(V_{\infty}-V_{\min }\right) e^{A} \\
x>3.0 D: A=\left[-0.5(r /(0.075(x-R)))^{2}\right]\end{array}$ & (13) \\
\hline & Lam-Wang & $\begin{array}{l}V_{x, r}=V_{\infty}-\left(V_{\infty}-V_{\min }\right) e^{A} \\
x>2.5 D: A=\left[-0.07(r /(0.204(x-R)))^{2}\right.\end{array}$ & (14) \\
\hline
\end{tabular}

To sum up, Fig. 13 shows the contour plot of the axial velocity of turbine wake along the axial direction $(\lambda=3.2)$. The axial velocity of turbine wake is gradually recovered to the magnitude of the incoming flow along the axial direction, and two velocity valleys of radial distribution appear in the zone of flow establishment and only one velocity valley appears in the zone of established flow. The predicted profile of turbine wake can be finally given as Fig. 14. 


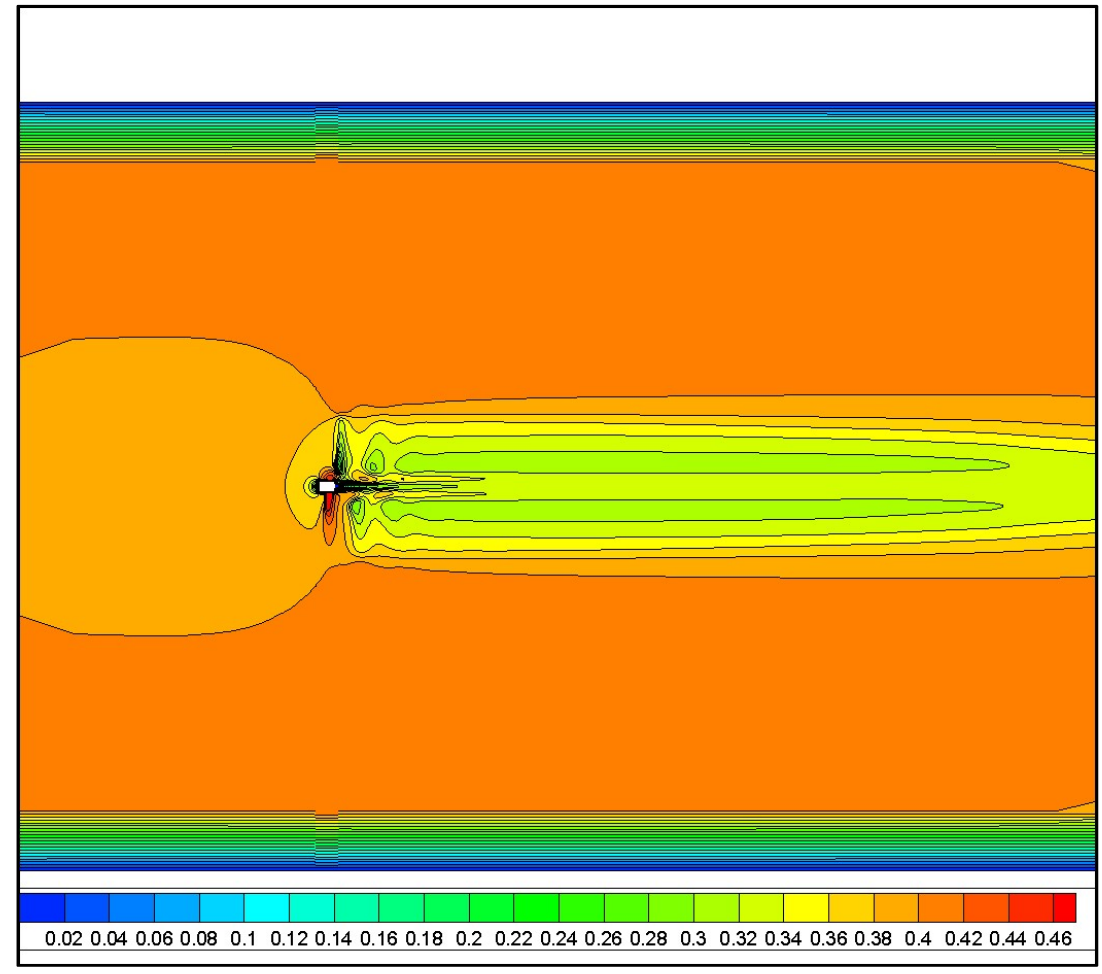

Fig. 13 The velocity profile along the axial direction of the axial velocity with $\lambda=3.2$

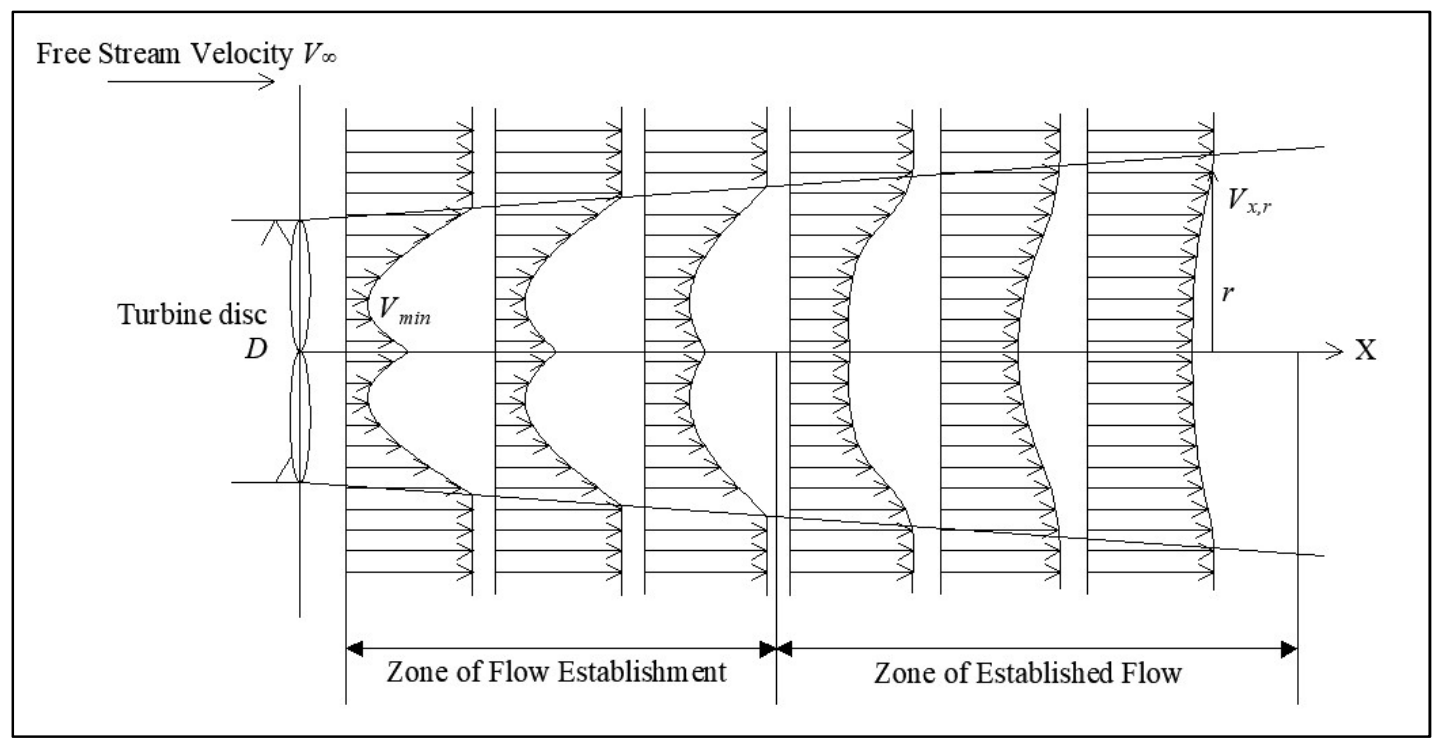

Fig. 14 The axial velocity distribution in the zone of flow establishment and established flow

\subsection{Tangential velocity}

In contrast to the submerged hole jet, the rotation of tidal current turbine causes the surrounding fluid to make a rotational movement around the rotating axis, creating a tangential velocity. It is contradictory with the assumption of axial momentum theory that "the energy supplied to the disc is, in turn, supplied to the fluid without any rotational effects being induced". The tangential velocity and radial velocity distribution of tidal current turbine wake are studied based on CFD results and 
experimental results conducted by lam in this paper.

\subsubsection{Position of the maximum tangential velocity}

The position of the maximum tangential velocity of turbine wake occurs at the middle of the blade and shifts radially toward the tip of blade with the tip speed ratio increases. CFD results show that the position of maximum tangential velocity $r / R$ are $0.36,0.56$ and 0.58 with the tip speed ratio $\lambda=1.6,2.7,3.2$ on the turbine blade surface $(x / D=0.1)$, respectively. Table 14 shows the position of the maximum tangential velocity on the surface of blade for turbine wake. Compared with the position of maximum tangential velocity of propeller jet, the maximum tangential velocity of turbine wake only occurs in one position and the position is closer to the middle of blade.

Table 14 The position of the maximum tangential velocity on the surface of blade

\begin{tabular}{cccc}
\hline Type & Researcher & Equation & No. \\
\hline \multirow{3}{*}{ Tidal turbine } & & $r / R=0.36 \quad \lambda=1.6$ & \\
& \multirow{2}{*}{ Lam-Wang } & $r / R=0.56 \quad \lambda=2.7$ & (15) \\
& & $r / R=0.58 \quad \lambda=3.2$ & \\
\hline
\end{tabular}

\subsubsection{Decay of the maximum tangential velocity}

As the wake develops downstream, the tangential velocity gradually decays in the axial direction. As shown in Table 15, when the tip speed ratio $\lambda=1.6$, the maximum dimensionless tangential velocity $V_{t} / V_{\infty}$ on the turbine blade surface $(x / D=0.1)$ is 0.5133 . When the axial distance $x / D \geq 1.1$, the maximum dimensionless tangential velocity is 0.0283 , only $2.83 \%$ of the free stream velocity, thus the effects of tangential velocity on turbine wake can be neglected. The CFD numerical simulation results show that the maximum tangential velocity decreases and the decay rate of tangential velocity increases with the increase of tip speed ratio. The maximum dimensionless tangential velocity on the blade surface $(x / D=0.1)$ decreases from 0.5133 to 0.2481 as the tip speed ratio increases from 1.6 to 3.2. In the region of $x / D=0.1 \sim 0.5$, the maximum dimensionless velocity decays by $86.93 \%, 95.58 \%$ and $97.70 \%$ with tip speed ratios $\lambda=1.6,2.7,3.2$.

Fig. 15 shows the axial distribution of the maximum tangential velocity for propeller jet and turbine wake. The trend of the maximum tangential velocity of the turbine wake in the axial direction is the same as the experimental results of propeller jet. Compared with the propeller jet, the maximum dimensionless tangential velocity $V_{t} / n D$ of turbine wake is less than that of propeller jet. The maximum tangential velocity of turbine wake decays faster and the impact is also less obvious. Table 16 shows the empirical equations for the decay of the maximum tangential velocity. 
Table 15 The maximum dimensionless tangential velocity $V_{t} / V_{\infty}$ at different cross-sections

\begin{tabular}{cccc}
\hline$x / D$ & \multicolumn{3}{c}{ Tip speed ratio $\lambda$} \\
& 1.6 & 2.7 & 3.2 \\
\hline 0.1 & 0.5133 & 0.3165 & 0.2481 \\
0.3 & 0.1755 & 0.0879 & 0.0564 \\
0.5 & 0.0978 & 0.0390 & 0.0128 \\
0.7 & 0.0671 & 0.0140 & 0.0057 \\
0.9 & 0.0475 & 0.0052 & 0.0025 \\
1.1 & 0.0283 & 0.0027 & 0.0016 \\
\hline
\end{tabular}

Table 16 Decay of the maximum tangential velocity

\begin{tabular}{clcc}
\hline Type & Researcher & Equation & No. \\
\hline \multirow{2}{*}{ Tidal turbine } & Lam-Wang & $\frac{V_{t(\max )}}{V_{0}}=0.0004\left(\frac{x}{D}\right)^{-2.157}$ & (16) \\
\hline
\end{tabular}

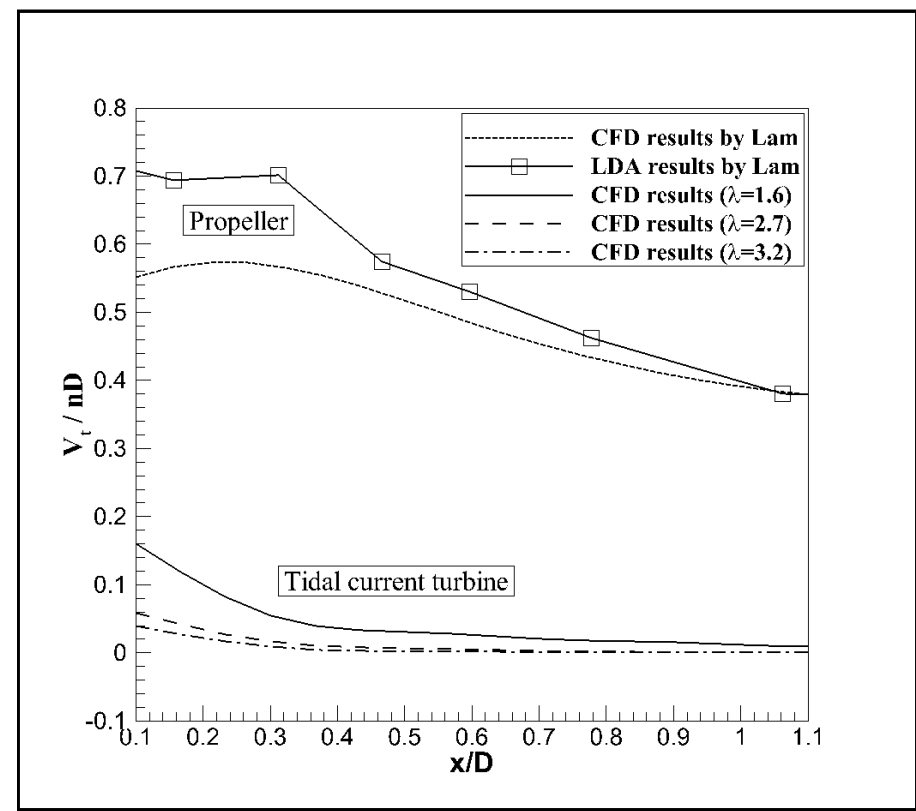

Fig. 15 The axial distribution of the maximum tangential velocity

\subsubsection{Lateral velocity distribution of tangential velocity}

Inside of the turbine disc, the tangential velocity of turbine wake increases firstly and then decreases in the radial direction from the rotating axis of the turbine. The radial distribution of tangential velocity shows two velocity peaks (one peak on each side), and the peak occurs at the position of the maximum tangential velocity. As shown in Fig. 16, CFD results show that the peak occurs at $r / R=0.36$ when the tip speed ratio $\lambda=1.6$. This is different from the experimental results and CFD results of propeller jet conducted by Lam. Experimental measurements of propeller jet show that there are two velocity peaks along the radial distribution of the tangential velocity, 
one near the hub and the other near the tip of the propeller. CFD results by Lam also did not get the two peak velocity, but the results showed a flat top peak from $r / R=0.2$ to $r / R=0.73$. The non-dimensional maximum tangential velocity $V_{t} / n D$ is 0.49 and less than the tangential velocity component of propeller jet.

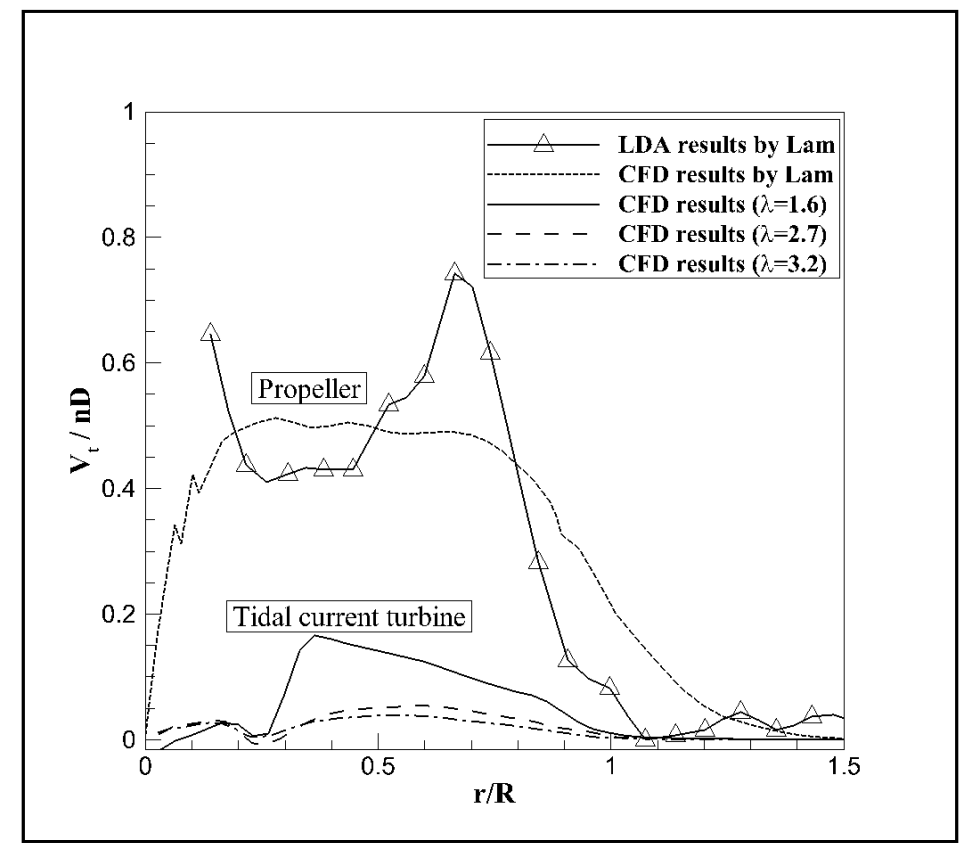

Fig. 16 The radial distribution of the tangential velocity $(x / D=0.1)$

\subsection{Radial velocity}

The radial velocity causes the divergence of turbine wake. As the wake develops downstream, the exchange of energy and momentum takes place inside and outside the stream boundary, resulting in a radial velocity component and leading to an enlarged wake range. Differing from the propeller jet diffusion, the internal velocity of turbine wake is smaller than that of the surrounding free flow, and external fluid flows inwards, reducing its velocity, finally resulting in an enlarged wake range.

\subsubsection{Position of the maximum radial velocity}

The position of the maximum radial velocity of turbine wake occurs at the middle of the blade. As the tip speed ratio increases, the position shifts radially toward the blade root. CFD results show that the position $r / R$ of maximum radial velocity of turbine wake on the turbine blade surface $(x / D=0.1)$ are $0.24,0.18,0.16$ with tip speed ratios $\lambda=1.6,2.7,3.2$, respectively. The position of the maximum radial velocity on the surface of blade for turbine wake is shown in Table 17. 
Table 17 The position of the maximum radial velocity on the surface of blade

\begin{tabular}{cccc}
\hline Type & Researcher & Equation & No. \\
\hline \multirow{3}{*}{ Tidal turbine } & & $r / R=0.24 \quad \lambda=1.6$ & \\
& Lam-Wang & $r / R=0.18 \quad \lambda=2.7$ & (17) \\
& & $r / R=0.16 \quad \lambda=3.2$ & \\
\hline
\end{tabular}

\subsubsection{Decay of the maximum radial velocity}

The radial velocity of turbine wake is small. It gradually decays along the axial direction and the decay rate increases with the tip speed ratio increases. As shown in Table 18 , the maximum dimensionless radial velocity $V_{r} / V_{\infty}$ on the blade surface $(x / D=0.1)$ is only 0.1830 with tip speed ratio $\lambda=2.7$, and the negative value represents the fluid moving toward the rotating axis. Fig. 17 shows the axial distribution of the maximum radial velocity. In the downstream area of $x / D=0.1 \sim 0.5$, the maximum dimensionless radial velocities decay by $21.44 \%$, $57.60 \%$ and $66.31 \%$ with tip speed ratios $\lambda=1.6,2.7,3.2$, respectively. As the wake develops downstream, the radial velocity decays close to 0 . Table 19 shows the empirical equation for the decay of the maximum radial velocity based on the numerical results with the DES-SA turbulence model. Because of the smallest proportion of the radial velocity of turbine wake velocity, the influence on the wake is insignificant compared with the axial velocity and the tangential velocity. The accurate prediction of the radial velocity needs a finer numerical simulation.

Table 18 The maximum dimensionless radial velocity $V_{r} / V_{\infty}$ at different cross-sections

\begin{tabular}{cccc}
\hline$x / D$ & \multicolumn{3}{c}{ Tip speed ratio $\lambda$} \\
& 1.6 & 2.7 & 3.2 \\
\hline 0.1 & -0.1399 & -0.1830 & -0.1787 \\
0.3 & -0.1099 & -0.0776 & -0.0602 \\
0.5 & -0.0731 & -0.0382 & -0.0210 \\
0.7 & -0.0547 & -0.0141 & -0.0043 \\
0.9 & -0.0345 & -0.0075 & -0.0067 \\
1.1 & -0.0155 & -0.0098 & -0.0114 \\
\hline
\end{tabular}

Table 19 Decay of the maximum radial velocity

\begin{tabular}{cccc}
\hline Type & Researcher & Equation & No. \\
\hline Tidal turbine & Lam-Wang & $\frac{V_{r(\max )}}{V_{0}}=0.0114 \ln \left(\frac{x}{D}\right)+0.0013$ & (18) \\
\hline
\end{tabular}




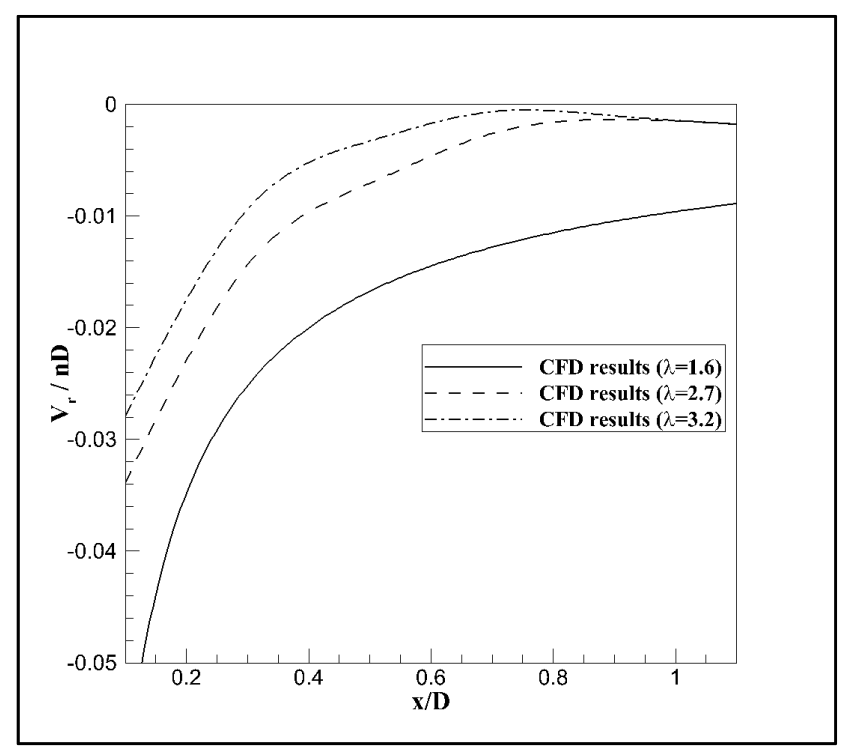

Fig. 17 The axial distribution of the maximum radial velocity

\subsubsection{Lateral velocity distribution of radial velocity}

Inside of the turbine disc, the radial velocity increases firstly and then decreases in the radial direction from rotating axis of the turbine. The radial velocity distribution of the radial velocity shows two peaks (one peak on each side), and the peak occurs at the position of the maximum radial velocity. The negative value represents the fluid flows to the rotating axis. As shown in Fig. 18, CFD results show that the peak of radial velocity occurs at $r / R=0.23$, when tip speed ratio $\lambda=1.6$. The value of radial velocity is positive for propeller jet and negative for turbine wake. It is mainly attributed to the difference working mechanisms of propeller and turbine. The velocity of propeller jet is faster than that of the surrounding stationary fluid and the internal fluid flows outward, resulting in the enlargement of the jet. But for the turbine wake, the internal velocity is smaller than that of the surrounding free flow, and external fluid flows inwards, reducing its velocity, finally resulting in an enlarged wake range. 


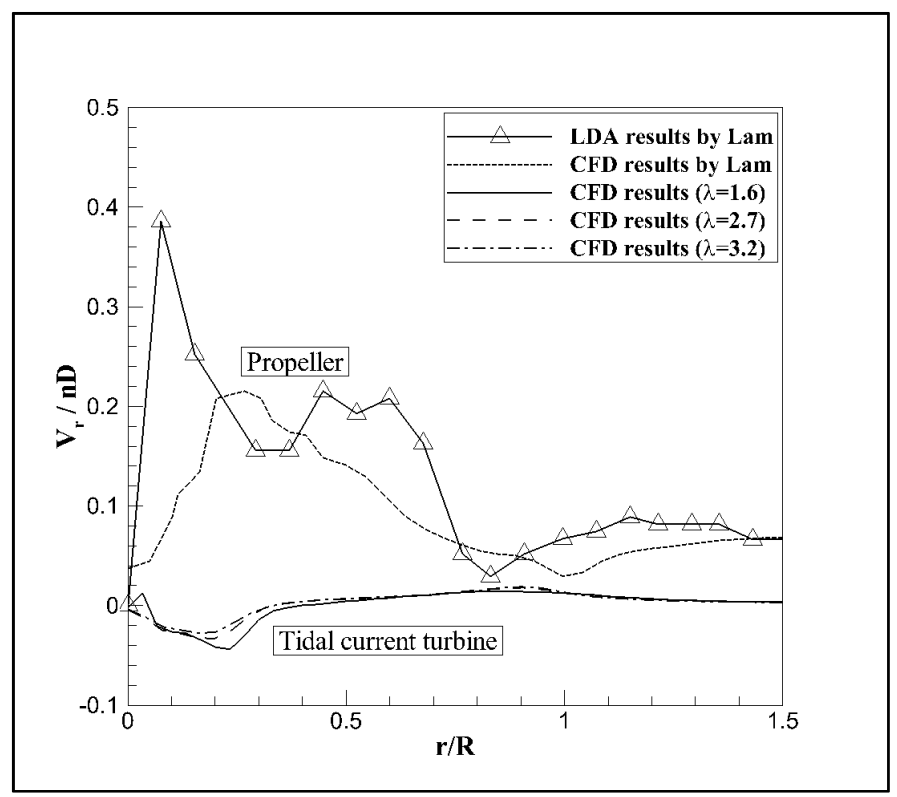

Fig. 18 The radial distribution of the radial velocity $(x / D=0.1)$

\section{Conclusion}

A numerical method is developed to study the turbine wake of a horizontal-axis turbine using the DES model. Several empirical equations for three velocity components of turbine wake are proposed by comparing CFD results with previous experimental and theoretical results. In summary, the contributions made through this study are:

(1) The efflux velocity of horizontal axis turbine wake decrease with the increase of the tip speed ratio and the position is deviated to tip along radial direction. The axial velocity inside the turbine disc is increased first, decreases and then increases along the radial direction. The axial velocity outside the turbine disc is slightly larger than the free flow.

(2) The zone of flow establishment and zone of established can be divided according to the minimum axial velocity position. There is no constant minimum axial velocity in the zone of flow establishment, but the position remains fixed. The minimum axial velocity gradually recovered along the axial direction of the turbine. The axial velocity distribution along the radial direction has two peaks which occurs at the position of the minimum axial velocity. The minimum axial velocity in the zone of established occurs on the axis of rotation, which is gradually recover to the free flow. There is only one peak of axial velocity along the radial direction.

(3) The tangential velocity is the second velocity component of the turbine wake. The maximum tangential velocity decays along the axis direction and two peaks occurs along the radial direction which is the position of the maximum tangential velocity. 
(4) The radial velocity component is relatively small. The maximum radial velocity decays along the axis direction and two peaks is occurred along the radial direction which is the position of the maximum radial velocity. The negative radial velocity indicates the fluid moves toward the rotation axis.

(5) The research reveals the complex wake structure of horizontal axis turbine and found the axial velocity component is the main influence factor of the wake distribution. A wake model of axial velocity for horizontal axis turbine is proposed without considering the effect of hub based on the axial velocity distribution in the zone of flow establishment and zone of established (Fig. 19).

(6) Based on CFD results using the DES-SA model, several empirical equations are finally proposed to describe the velocity distribution of turbine wake (Table 20).

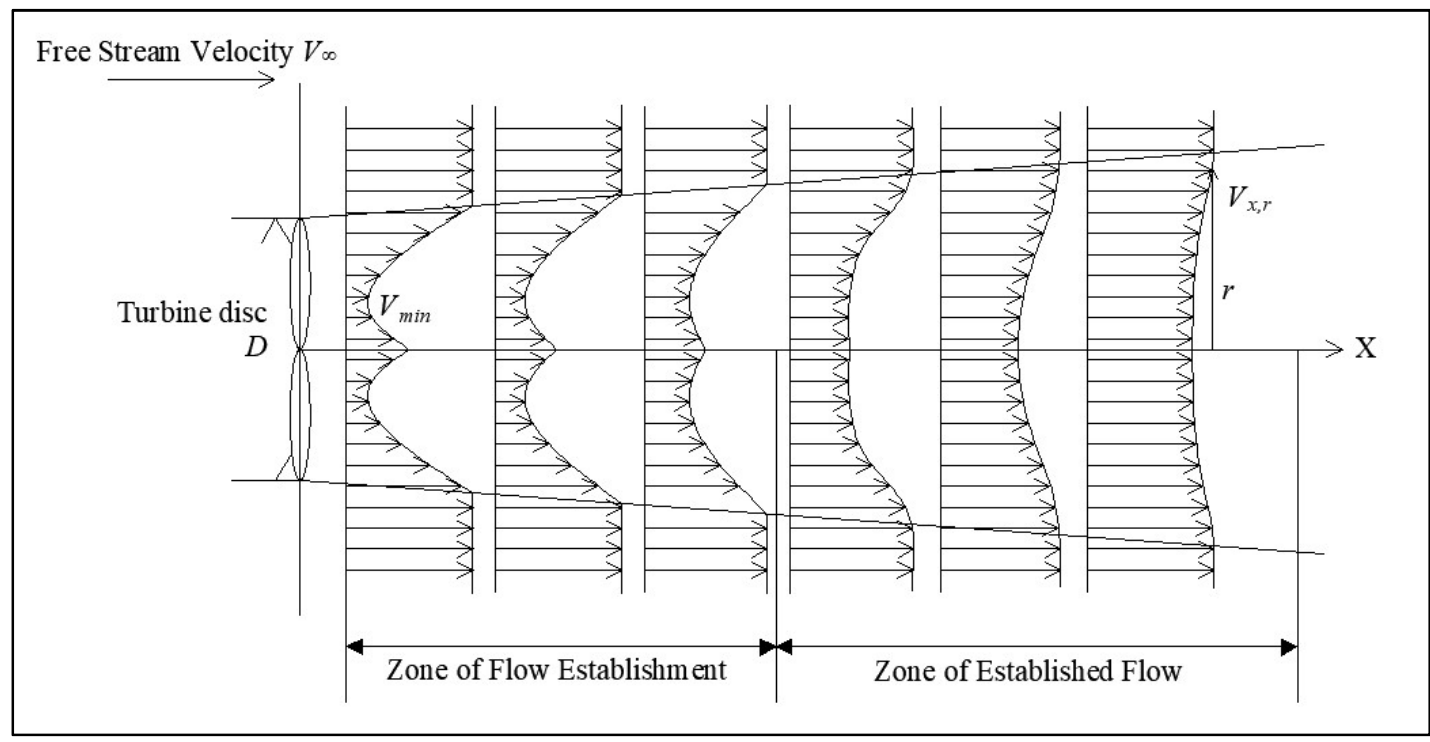

Fig. 19 The axial velocity distribution in the zone of flow establishment and established flow 
Table 20 The equations of turbine wake based on DES-SA model

\begin{tabular}{|c|c|}
\hline Calculation item & Equation \\
\hline The efflux velocity & 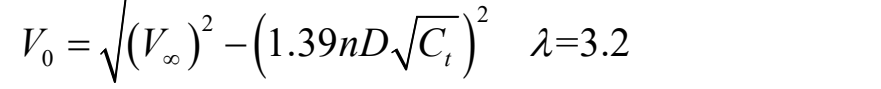 \\
\hline $\begin{array}{c}\text { The position of efflux } \\
\text { velocity }\end{array}$ & $R_{m o}=0.27\left(R-R_{h}\right)$ \\
\hline $\begin{array}{l}\text { Recovery of the } \\
\text { minimum axial } \\
\text { velocity }\end{array}$ & $\frac{V_{\min }}{V_{0}}=0.0509\left(\frac{x}{D}\right)+0.742$ \\
\hline $\begin{array}{c}\text { The length of flow } \\
\text { establishment }\end{array}$ & $\begin{array}{ll}x / D=1.5 & \lambda=1.6 \\
x / D=2.0 & \lambda=2.7 \\
x / D=2.5 & \lambda=3.2\end{array}$ \\
\hline $\begin{array}{l}\text { The radial } \\
\text { distribution of axial } \\
\text { velocity in the zone } \\
\text { of flow establishment }\end{array}$ & $\begin{array}{l}V_{x, r}=V_{\infty}-\left(V_{\infty}-V_{\min }\right) e^{A} \\
x \leq 0.5 D: A=\left[-0.07\left(\left(r-R_{m 0}\right) /\left(\frac{R_{m 0}}{2}\right)\right)^{2}\right] \\
0.5 D<x \leq 2.5 D: A=\left[-0.07\left(\left(r-R_{m 0}\right) /\left(\left(\frac{R_{m 0}}{2}\right)-0.204(x-R)\right.\right.\right.\end{array}$ \\
\hline $\begin{array}{l}\text { The radial } \\
\text { distribution of axial } \\
\text { velocity in the zone } \\
\text { of established flow }\end{array}$ & $\begin{array}{l}V_{x, r}=V_{\infty}-\left(V_{\infty}-V_{\min }\right) e^{A} \\
x>2.5 D: A=\left[-0.07(r /(0.204(x-R)))^{2}\right]\end{array}$ \\
\hline $\begin{array}{c}\text { The position of } \\
\text { maximum tangential } \\
\text { velocity on the } \\
\text { surface of blade }\end{array}$ & $\begin{array}{ll}r / R=0.36 & \lambda=1.6 \\
r / R=0.56 & \lambda=2.7 \\
r / R=0.58 & \lambda=3.2\end{array}$ \\
\hline $\begin{array}{c}\text { Decay of the } \\
\text { maximum tangential } \\
\text { velocity }\end{array}$ & $\frac{V_{t(\max )}}{V_{0}}=0.0004\left(\frac{x}{D}\right)^{-2.157}$ \\
\hline $\begin{array}{l}\text { The position of } \\
\text { maximum radial } \\
\text { velocity on the } \\
\text { surface of blade }\end{array}$ & $\begin{array}{ll}r / R=0.24 & \lambda=1.6 \\
r / R=0.18 & \lambda=2.7 \\
r / R=0.16 & \lambda=3.2\end{array}$ \\
\hline $\begin{array}{l}\text { Decay of the } \\
\text { maximum radial } \\
\text { velocity }\end{array}$ & $\frac{V_{r(\max )}}{V_{0}}=0.0114 \ln \left(\frac{x}{D}\right)+0.0013$ \\
\hline
\end{tabular}




\section{Acknowledgements}

This research was funded by the Natural Science Foundation of Tianjin City: 18JCYBJC21900, Science Fund for Creative Research Groups of the National Natural Science Foundation of China (Grant no. 51621092) and Beiyang Scholar Foundation. Authors wish to express gratitude to the editor and anonymous reviewers to improve our research works.

\section{Nomenclature}

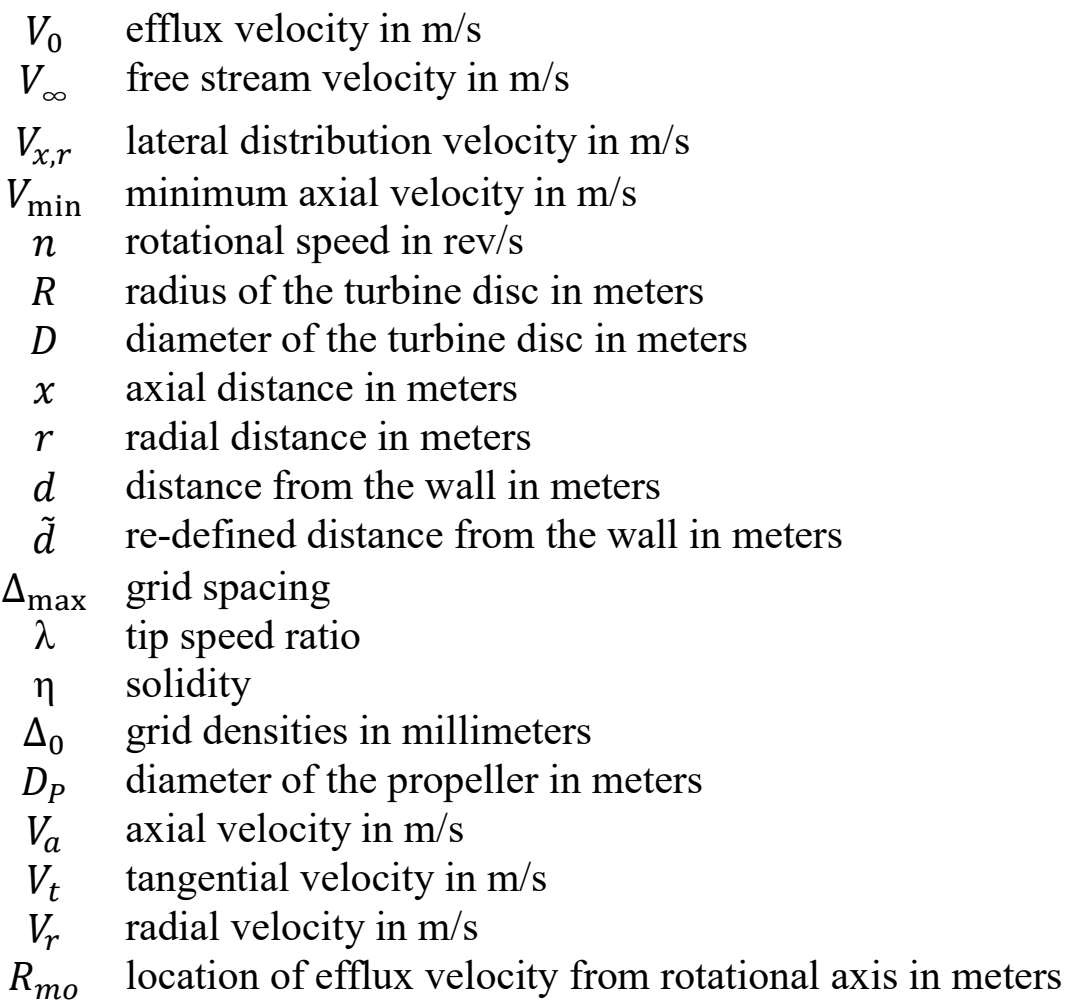

\section{References}

[1] World Energy Outlook Special Report 2016. Energy and Air Pollution; 2016.

[2] Esteban M, Leary D. Current developments and future prospects of offshore wind and ocean energy. Applied Energy 2012; 90(1):128-36.

[3] Wang CW, Lu W. Marine Energy Resource Analysis Methods and Reserves Evaluation. Ocean Press 2009.

[4] Sanderse B. Aerodynamics of wind turbine wakes. Energy Research Center of the Netherlands (ECN), ECN-E-09-016, Petten, The Netherlands, Tech Rep 2009; 5(15): 153 .

[5] Rankin W. On the mechanical principles of the action of propellers. Trans Inst Naval Architects 1865; 6:13-39.

[6] Froude W. On the elementary relation between pitch, slip, and propulsive efficiency. 1920.

[7] O'Brien TP. The Design of Marine Screw Propellers: Hutchinson Scientific \& Technical. 1962.

[8] Lerbs HW. Moderately loaded propellers with a finite number of blades and 
arbitrary distribution of circulation. Trans SNAME 1952; 60:73-123.

[9] Pien PC. The calculation of marine propellers based on lifting surface theory. Journal of Ship Research 1961; 5(2):1-14.

[10] Kerwin JE, Kinnas SA, Lee J-T,et al. A surface panel method for the hydrodynamic analysis of ducted propellers. MASSACHUSETTS INST OF TECH CAMBRIDGE DEPT OF OCEAN ENGINEERING 1987.

[11] Albertson ML, Dai Y, Jensen RA,et al. Diffusion of submerged jets[J]. Transactions of the American Society of Civil Engineers 1950; 115(1):639-64.

[12] Blaauw H, Van de Kaa E. Erosion of bottom and sloping banks caused by the screw race of manoevring ships: Delft Hydraulics 1978.

[13] Berger W, Felkel K, Hager M,et al. Courant provoque par les bateaux protection des berges et solution pour eviter l'erosion du lit du haut rhin. PIANC, 25th Congress 1981.

[14] Verhey H. The stability of bottom and banks subjected to the velocities in the propeller jet behind ships. International Harbour Congress, 8th 1983.

[15] Hamill GA. Characteristics of the screw wash of a manoeuvring ship and the resulting bed scour. Queen's University of Belfast; 1987 [Ph.D. thesis].

[16] Lam WH, Chen L. Equations used to predict the velocity distribution within a wake from a horizontal-axis tidal-current turbine. Ocean Engineering 2014; 79:35-42.

[17] Lam WH, Chen L, Hashim R. Analytical wake model of tidal current turbine. Energy 2015; 79:512-21.

[18] Jiang J, Lam W H, Cui Y, et al. Ship Twin-propeller Jet Model used to Predict the Initial Velocity and Velocity Distribution within Diffusing Jet. KSCE Journal of Civil Engineering, 2019, 23(3): 1118-1131.

[19] Ma Y, Lam W H, Cui Y, et al. Theoretical vertical-axis tidal-current-turbine wake model using axial momentum theory with CFD corrections. Applied Ocean Research, 2018, 79: 113-122.

[20] Zhang T, Lam W H, Cui Y, et al. Tip-Bed Velocity and Scour Depth of Horizontal-Axis Tidal Turbine with Consideration of Tip Clearance. Energies, 2019, 12(12): 2450.

[21] Sun C, Lam W H, Cui Y, et al. Empirical model for Darrieus-type tidal current turbine induced seabed scour. Energy conversion and management, 2018, 171: 478-490.

[22] Li, Y and Calisal, S.M., "A discrete vortex method for simulating a stand-alone tidal current turbine: modeling and validation", Journal of Offshore Mechanics and Arctic Engineering, 2010, 132(3), p 1102-1110

[23] Churchfield,M. Li,Y., and Moriarty,P.A large - eddy simulation study of wake propagation and power production in an array of tidal current turbines, Philosophical Transactions of the Royal Society of London A: Mathematical and Physical Sciences, 2013.1.14, 371(1985)

[24] Kang, S., Yang, X., and Sotiropoulos, F., On the Onset of Wake Meandering for an Axial Flow Turbine in a Turbulent Open Channel Flow, Journal of Fluid Mechanics, 2014, 744, 376-403. 
[25] Spalart PR, Jou WH, Strelets M, et al. Comments on the Feasibility of LES for Wings, and on a Hybrid RANS/LES Approach. Advances in DNS/LES 1997; 1: 4-8.

[26] Ferreira CS, Bijl H, Van Bussel G, et al. Simulating dynamic stall in a 2D VAWT: modeling strategy, verification and validation with particle image velocimetry data. Journal of physics: conference series. IOP Publishing 2007; 75(1): 012023.

[27] Travin A, Shur M, Strelets M, et al. Detached-Eddy Simulations Past a Circular Cylinder[J]. Flow Turbulence \& Combustion 2000; 63(1-4):293-313.

[28] Li ZH, Zhang JF, Tao WQ. DES turbulence model simulation for flow around circular cylinder at $\mathrm{Re}=3900$. Journal of Engineering Thermophysics 2013; 9:1703-1706.

[29] Xiao ZX, Chen HX, Li QB, Fu S. Simulation of separation flows with RANS/LES hybrid methods. ACTA AERODYNAMICA SINICA 2006; 24(2):218-222.

[30] Zhang YN, Liu SH, Wu YL, Yang JM. DES simulation on Francis turbine with new guide vanes. Journal of Engineering Thermophysics 2007; 28(s1):139-141.

[31] Huang JF, Zhang LX, Wang WQ, Yao J. Fine simulation of 3-D unsteady flows in a Francis hydro-turbine on Detached Eddy Simulation. Zhongguo Dianji Gongcheng Xuebao (Proceedings of the Chinese Society of Electrical Engineering). Chinese Society for Electrical Engineering 2011; 31(26): 83-89.

[32] Spalart PR, Deck S, Shur M L, et al. A New Version of Detached-eddy Simulation, Resistant to Ambiguous Grid Densities. Theoretical \& Computational Fluid Dynamics 2006; 20(3):181.

[33] Spalart PR. Detached-Eddy Simulation. Annual Review of Fluid Mechanics 2009; 41(41):203-229.

[34] Whale J. Study of the near wake of a model wind turbine using particle image velocimetry. The university of Edinburgh; 1996 [Ph.D. thesis].

[35] Fluent A. ANSYS fluent theory guide 15.0[J]. Inc, Canonsburg, PA.2013.

[36] Philippe RS. Young-Person"s Guide to Detached-Eddy Simulation Grids. NASA Langley Technical Report Server 2001.

[37] Maganga F, Germain G, King J, Pinon G, Rivoalen E. Experimental characterisation of flow effects on marine current turbine behaviour and on its wake properties. IET Renewable Power Generation 2010; 4(6):498-509.

[38] Wang S, Lam W H, Cui Y, et al. Novel energy coefficient used to predict efflux velocity of tidal current turbine[J]. Energy, 2018, 158: 730-745.

[39] Lam, WH. Simulations of a ship's propeller jet. Queen's University of Belfast; 2008 [Ph.D. thesis].

[40] Lam WH, Hamill GA, Robinson DJ, et al. Semi-empirical methods for determining the efflux velocity from a ship's propeller. Applied Ocean Research 2012; $35: 14-24$. 